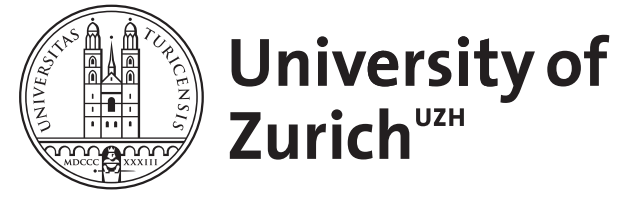

Zurich Open Repository and Archive

University of Zurich

University Library

Strickhofstrasse 39

CH-8057 Zurich

www.zora.uzh.ch

Year: 2017

\title{
Die Bindung der EU-Mitgliedstaaten an die Grundrechtecharta in einer europäisierten Strafrechtspflege
}

\author{
Meyer, Frank
}

DOI: https://doi.org/10.1515/zstw-2016-0033

Posted at the Zurich Open Repository and Archive, University of Zurich ZORA URL: https://doi.org/10.5167/uzh-139302

Journal Article

Published Version

Originally published at:

Meyer, Frank (2017). Die Bindung der EU-Mitgliedstaaten an die Grundrechtecharta in einer europäisierten Strafrechtspflege. ZStW: Zeitschrift für die gesamte Strafrechtswissenschaft, 128(4):10891140 .

DOI: https://doi.org/10.1515/zstw-2016-0033 


\section{Professor Dr. Frank Meyer, LL.M. (Yale)* Die Bindung der EU-Mitgliedstaaten an die Grundrechtecharta in einer europäisierten Strafrechtspflege}

\section{Einleitung}

Die Charta der Grundrechte der Europäischen Union ist weder eine föderale Europäische Bill of Rights ${ }^{1}$ noch ein allumfassender, einheitlicher Grundrechtskatalog für alle Menschen auf dem Territorium der Europäischen Union². Sie ist Bestandteil eines Mehrebenengrundrechtsverbundes, der speziell der Ausübung supranationaler Hoheitsgewalt seitens der Europäischen Union Grundrechtsbindungen auferlegt. Dabei steht die GRC in einer komplexen Beziehung sowohl zu den nationalen Grundrechtskatalogen als auch zur EMRK. Nationale Grundrechte werden im Geltungsbereich der Charta nicht zwangsläufig verdrängt, sondern können (unter praktisch nicht leicht zu handhabenden Voraussetzungen, s.u.) parallel anwendbar bleiben. Die Mindestgarantien der EMRK fließen wiederum materiell über Art. 52 Abs. 3 GRC in die GRC ein ${ }^{3}$. Auch wenn die Mehrzahl der Konventionsrechte schon zuvor im Gewand allgemeiner Rechtsgrundsätze des Unionsrechts anerkannt waren (und sich mit Inkrafttreten der GRC auch nichts an deren Existenz und Inhalten geändert hat, welche ihnen die Unionsgerichte zuschreiben), ergibt sich daraus ein wesentlicher Unterschied zur Rechtslage vor Inkrafttreten der GRC. Denn die verbindlichen Mindestgehalte sind aufgrund der vorgenannten Schutzniveauklausel konkret nach den spezifischen Ausgestaltun-

1 So aber Reding, SPEECH/12/403; vgl. dazu auch Absatz V der Präambel und dessen Entstehungsgeschichte, Jürgen Meyer, in: ders. (Hrsg.), Charta der Grundrechte der europäischen Union, 4. Aufl. 2014, Präambel, Rdn. 45, 47.

2 Ohler, NVwZ 2013, 1433, 1435; Art. 2 EUV führt als Grundnorm nicht zu allgemeiner Anwendbarkeit der GRC. Art. $51 \mathrm{GRC}$ ist lex specialis.

3 Borowsky, in: Jürgen Meyer (Anm. 1), Art. 52 Rdn. 29. Diese Schutzniveauklausel verknüpft den Geltungsumfang der GRC mit der EMRK.

*Kontaktperson: Frank Meyer, Inhaber des Lehrstuhls für Strafrecht und Strafprozessrecht unter Einschluss des internationalen Strafrechts an der Universität Zürich. 
gen zu bestimmen, welche das Konventionsrecht in der Spruchpraxis des EGMR erfahren hat ${ }^{4}$. Sie unterliegen damit (zumindest partiell) weit weniger der autonomen Definition und Ausformung durch die Unionsgerichte ${ }^{5}$. Umgekehrt können und sollen die Schutzbereiche der GRC über die EMRK, aber auch über das nationale Verfassungsrecht hinausreichen. Die GRC-Rechte sind nicht als Mindestgarantien $\mathrm{zu}$ verstehen. Sie sind in Bezug auf die verschiedenen Formen und Dimensionen supranationaler Hoheitsgewalt in der EU wie ein nationaler Grundrechtskatalog vollständig zur Entfaltung zu bringen. Dabei gilt es den verschiedenen Geltungsdimensionen der GRC Rechnung zu tragen. Der Unionsbürger wird durch die GRC nicht mehr nur (analog zur EMRK) in seinem Mitgliedstaat gegen dessen Hoheitsausübung (beim indirekten Unionsvollzug) geschützt, sondern als Bürger der EU auch transnational-vertikal gegenüber der Ausübung supranationaler Hoheitsgewalt durch deren Organe und Einrichtungen (insb., aber nicht nur, beim direkten Vollzug von Unionsrecht). Zusätzlich ist der GRC eine transnational-horizontale (mithin grenzübergreifende) Geltungsdimension eigen, welche die Wirkungen multipler Eingriffe in verschiedenen Ländern und durch verschiedene Akteure auf der Grundlage bzw. innerhalb des Geltungsbereichs des Unionsrechts gegenüber den Unionsbürgern aufgreifen kann ${ }^{6}$. Dem europäischen Grundrechtsverbund wird damit eine Geltungsdimension hinzugefügt, die weder durch nationale Grundrechte noch durch die EMRK abgedeckt, aber für eine europäisierte Strafrechtspflege von fundamentaler Bedeutung ist. Das nationale Schutzniveau in den (nicht abgedeckten) transnationalen Geltungsbereichen erfährt dadurch einen beträchtlichen Aufwuchs.

Die Anwendbarkeit der GRC ist in Art. 51 GRC geregelt. Art. 51 GRC gehört neben Art. 52 und Art. 53 GRC zu den Schlüsselnormen im Mehrebenengrundrechtsverbund der EU. Die Charta gilt danach umfassend für das Handeln der Organe und Einrichtungen der Union; für die Mitgliedstaaten jedoch „ausschließ-

\footnotetext{
4 Art. 52 Abs. 3 GRC bewirkt mithin einen materiellen Beitritt zur EMRK, Borowsky, in: Jürgen Meyer (Anm. 1), Art. 52 Rdn. 35; Ziegenhorn, Der Einfluss der EMRK im Recht der EU-Grundrechtecharta, 2009, S. 145, 151. Wenn Lenaerts, EuR 2012, 3, 13, ausführt, dass Art. 52 Abs. 3 GRC nichts anderes darstellt als die Kodifizierung der Rechtsprechung des EuGH, wonach der EMRK in der Auslegung durch den EGMR „,besondere Bedeutung“ für den Grundrechtsschutz in der EU zukommt, ist das vielleicht der Wunsch der Unionsgerichte, aber sachlich unzutreffend.

5 Borowsky, in: Jürgen Meyer (Anm. 1), Art. 52 Rdn. 30; Becker, in: Schwarze (Hrsg.), EU-Kommentar, 3. Aufl. 2012, Art. 52 GRC Rdn. 16; Peters/Altwicker, Europäische Menschenrechtskonvention, 2. Aufl. 2012, § 4 Rdn. 3.

6 Allg. Schorkopf, Enzyklopädie Europarecht, 2014,Bd. 2, § 3 Rdn. 15; Borowsky, in: Jürgen Meyer (Anm. 1), Art. 51 Rdn. 16; dezidiert zu ne bis in idem Eser, in: Jürgen Meyer (Anm. 1), Art. 50 Rdn. $11 \mathrm{ff}$.
} 
lich bei der Durchführung des Rechts der Union“. Der Anwendungsbereich der Charta bestimmt sich mithin institutionell und funktional, weshalb die Charta auf den jeweiligen Ebenen des EU-Mehrebenensystems und damit auch in verschiedenen Bereichen der europäisierten Strafrechtspflege in unterschiedlicher Breite und Tiefe gilt.

Bereits die Präzisierung des abstrakten Anwendungsbereichs der GRC sorgt immer noch für beträchtliche Schwierigkeiten und hat zu einer intensiven wissenschaftlichen Befassung mit dieser Frage im europäischen Schrifttum Anlass geboten. Das Strafrecht ist in dieser Diskussion bislang kaum hörbar. Im ersten Teil des Beitrags wird deshalb der gesicherte Erkenntnisstand zum Anwendungsbereich der GRC abstrakt erläutert und sodann für die EU-Strafrechtspflege präzisiert. Mit diesem Schritt ist gleichwohl - und gerade mit Blick auf die besonderen strafrechtlichen Fragestellungen - noch nicht viel gewonnen. $\mathrm{Zu}$ untersuchen bleibt die konkrete Reichweite und Tiefe der Bindungen, die aus der abstrakten Anwendbarkeit der GRC fließen. Die Klärung dieser Fragen ist nicht nur deshalb von enormer und zunehmender Relevanz, weil sich die institutionelle Architektur des Raums der Freiheit, der Sicherheit und des Rechts gegenwärtig in einem einschneidenden Umbruchprozess befindet, sondern auch deshalb, weil EuGH und Kommission mit Auslaufen der Übergangsperiode zum 1. 12. 2014 die vollumfängliche Kontrollgewalt über Instrumente und Einrichtungen der vormaligen dritten Säule erlangt haben ${ }^{7}$.

\section{Abstrakte Anwendbarkeit}

Während die Anwendbarkeit der GRC auf die Handlungen der Unionsorgane und -einrichtungen eindeutig geregelt und umfassend ist, kreist die Diskussion bezüglich der Mitgliedstaaten um die Formulierung „Durchführung des Rechts der Union“. Ihr zweiter Teil ist relativ klar. Unter Unionsrecht i.S. v. Art. 51 GRC sind Primärrecht, Sekundärrecht nach Art. 288 AEUV, Tertiärrecht sowie Übereinkommen zu verstehen'. Mit dem Terminus „Durchführung“ weicht die deutsche Fassung (und mit ihr eine Reihe weiterer nationaler Übersetzungen) hingegen von der tradierten Standardformel zur Begründung der Anwendbarkeit von Unions-

7 Zur Kontrollgewalt des EuGH im EU-Strafrecht nach Ablauf der Übergangsperiode Bachmaier, NJECL 6 (2015), S. 505, 508, 510, 512f.; Frank Meyer, Enzyklopädie Europarecht, 2014, Bd. 3, § 38 Rdn. $22 \mathrm{ff}$.

8 Ohler, NVwZ 2013, 1433.

9 Ohler, NVwZ 2013, 1433; Kingreen, in: Calliess/Ruffert (Hrsg.), EUV/AEUV, 4. Aufl. 2011, Art. 51 GRC Rdn. 8. 
grundrechten zu Zeiten des EGV ab ${ }^{10}$. Erforderlich war danach ein Handeln im

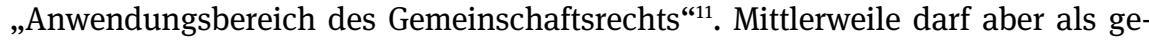
klärt gelten, dass mit dieser Textdiskrepanz in einzelnen Sprachfassungen keine Rücknahme des Schutzumfangs verbunden ist ${ }^{12}$. Vielmehr gelten die bisher anerkannten Fallgruppen weiter. Unter „Durchführung des Rechts der Union“ ist deshalb nicht nur europarechtlich direkt veranlasstes oder vollständig determiniertes Handeln der Mitgliedstaaten zu verstehen ${ }^{13}$, sondern auch die Ausfüllung von durch EU-Recht begründeten Umsetzungs- ${ }^{14}$ und Ermessensspielräumen ${ }^{15}$ (bei der Implementierung und Durchführung von Unionsrecht) sowie mitgliedstaatliches Handeln in unionsrechtlich geprägten Rechtsbereichen ${ }^{16}$. Zuletzt hat der EuGH die Anwendbarkeit der GRC auch für nationale Maßnahmen bestätigt, die Grundfreiheiten einschränken ${ }^{17}$. Art. 51 Abs. 1 GRC wird vom EuGH insgesamt

10 Andere amtliche Sprachfassungen sprechen dagegen vom Anwendungsbereich; Kokott/Sobotta, Europäische Grundrechte Zeitschrift, 2010, 265, 268.

11 Van den Eeckhout, Common Market Law Review, 39 (2002), S. 945, $963 \mathrm{ff}$.

12 Dies wurde schon früher mit der Entwicklungsgeschichte der GRC begründet. Diese lasse keine Intention erkennen, den vorherigen Anwendungsbereich der Unionsgrundrechte einzuschränken, Scheuing, EuR 2005, 162, 183f.; Ehlers, in: Ehlers (Hrsg.), Europäische Grundrechte und Grundfreiheiten, 4. Aufl. 2014, § 14 Rdn. 53. Die Begriffe „Durchführung“ und „Anwendungsbereich“ wurden alternierend verwendet. Die Erklärungen des Präsidiums des Konvents zu dieser Vorschrift nähmen vielmehr uneingeschränkt auf die EuGH-Rechtsprechung Bezug; Jarass, GRCKommentar, 2. Aufl. 2013, Art. 51 Rdn. 10; zum Stellenwert der Erläuterungen des Präsidiums des Konvents; Becker, in: Schwarze (Hrsg.), EU-Kommentar, 3. Aufl. 2012, Art. 52 Rdn. 15, 20; Ziegenhorn (Anm. 4), S. $59 \mathrm{ff}$.

13 Jarass, NJW 2011, 1393, 1394; a. A. schon zuvor Fassbender, NVwZ 2010, 1049, 1050; Huber, EuR 2008, 190, 197; Cremer, EuGRZ 2011, 545, 551.

14 EuGH, Rs. C-256/11 (Dereci), Slg. 2011, I-11315, Rdn. 72; EuGH, Urteil v. 12. 9. 2014, Rs. C-562/ 12 (Liivimaa Lihaveis MTÜ): Erlass nationaler Verwaltungs- und Verfahrensvorschriften fällt unter Durchführung des Unionsrechts, wenn diese ein Gremium betreffen, dessen Einrichtung das Unionsrecht verlangt, und sie der Umsetzung eines operationellen Unionsprogramms dienen; Jarass (Anm. 12), Art. 51 Rdn. 21; so schon für die Grundrechtsbindung vor Inkrafttreten der GRC EuGH, verb. Rs. C-379 u. C-380/08 (ERG), Slg. 2010, I-2007, Rdn. 79; EuGH, Rs. C-275/06 (Promusicae), Slg. 2008, I-271, Rdn. 68; EuGH Rs. C-555/07 (Kücükdeveci), Slg. 2010 I-365, Rdn. 23 ff. 15 EuGH, Urteil v. 21. 12. 2011, verb. Rs. C-411/10 und C-493/10 (N.S.u.a.), Slg. 2011, I-13905, Rdn. 64 ff.; Jarass (Anm. 12), Art. 51 Rdn. 21.

16 EuGH, Rs. C-279/09 (Deutsche Energiehandels- und Beratungsgesellschaft/Bundesrepublik Deutschland), Slg. 2010, I-13849, Rdn. 59ff.; EuGH Rs. C-617/10 (Åkerberg Fransson), Rdn. 16ff.; EuGH, Rs. C-405/10 (Garenfeld), Slg. 2011, I-11035, Rdn. 48.

17 EuGH, Rs. C-390/12 (Pfleger); Wollschläger, EuZW 2014, 577, 579 f. mit überzeugender Begründung der EuGH-Position; sie sei „im Interesse von Vorrang und einheitlicher Anwendbarkeit des Unionsrechts unerlässlich“; so schon zuvor Ohler, NVwZ 2013, 1433, 1435: Anwendbarkeit der Grundfreiheiten führt (weil unmittelbar geltendes Unionsrecht) zur Anwendbarkeit der GRC; Kahl/Schwind, EuR 2014, 170, 189 aus der Perspektive umfassend-kohärenten Individualrechts- 
weit und dynamisch verstanden ${ }^{18}$. Der Anwendungsbereich der Unionsgrundrechte verschiebt sich aus Sicht der Unionsgerichtsbarkeit mithin auch nach Inkrafttreten der GRC parallel zur Entwicklung des Anwendungsbereichs des Unionsrechts ${ }^{19}$.

Die genannten Fallgruppen sind im Einzelnen durchaus nicht unumstritten. So kritisieren Wissenschaft und nationale Gerichte im Bereich der Umsetzung und Durchführung von Unionsrecht, dass der EuGH eine Bindung unabhängig davon bejaht, ob Umsetzungs- und Ermessensspielräume bestehen ${ }^{20}$. Hierin wird eine erhebliche Gefahr der Unitarisierung des Grundrechtsschutzes ausgemacht, die eine Verdrängung ausdifferenzierter nationaler Grundrechtssysteme einschließlich gewachsener, effektiver Rechtsschutzsysteme bewirken könne ${ }^{21}$. Demgegenüber wird unter grundsätzlicher Einräumung möglicher Unitarisierungstendenzen nüchtern darauf hingewiesen, dass eine klare Grenzziehung (entlang der Gestaltungsräume) weder tatsächlich durchführbar noch konzeptionell überzeugend erscheint ${ }^{22}$. Autonome nationale Spielräume seien praktisch weit seltener als allgemein angenommen. Es werde übersehen, dass Gestaltungsfreiräume (der nationalen Parlamente) oftmals erst durch einen Unionsakt bzw. im Kontext eines solchen eröffnet werden. Bei der Ausübung solcher Konkretisierungsfunktionen haben die zuständigen nationalen Instanzen nicht nur die unionsrechtlich angestrebten Ziele zur Geltung zu bringen, sondern unterliegen mithin auch anderweitigen Vorgaben des Unionsrechts wie eben Richtlinienzielen, Grundrechten,

schutzes; zur Rechtslage vor Inkrafttreten der GRC EuGH, Rs. C-260/89 (ERT/D. E. Pliroforissis und S. Kouvelas), Slg. 1991, I-2925, Rdn. 42; EuGH, Rs. C-159/90 (Society for the Protection of Unborn Children Ireland/S. Grogan a. o.), Slg. 1991, I-4685, Rdn. 31; EuGH, Rs. C-368/95 (Familiapress/Bauer Verlag), Slg. 1997, I-3689, Rdn. 18; EuGH, Rs. C-292/97 (Karlsson), Slg. 2000, I-2737, Rdn. 37; EuGH, Rs. C-60/00 (Carpenter), Slg. 2002, I-6279, Rdn. 29, 30, 37; Jarass (Anm. 12), Art. 51 Rdn. 19.

18 Wollenschläger, Enzyklopädie Europarecht, 2014, Bd. 1, § 8 Rdn. 28, auch unter Hinweis auf die Erläuterungen zur GRC; zum Fallrecht des EuGH s. Craig/DeBúrca, EU Law, 6. Aufl. 2015, S. 410 ff., die auf die beträchtliche Zahl von Fällen hinweisen, in denen der EuGH die Anwendbarkeit verneint.

19 EuGH, Rs. C-617/10 (Åkerberg Fransson), Rdn. 21; Frenzel, Der Staat 2014, Vol. 53, No. 1: 1, $16 \mathrm{ff}$.

20 Es stünden „sich ein expansiver, (nicht nur) auf die Absicherung von Vorrang und einheitlicher Anwendbarkeit des Unionsrechts zielender Ansatz auf Unionsebene und ein auf die Wahrung mitgliedstaatlicher Gestaltungsspielräume bedachter nationaler Ansatz gegenüber“, Wollenschläger (Anm. 18), Bd. 1, § 8 Rdn. 16ff.; siehe auch Schorkopf (Anm. 6), Bd. 2, § 3 Rdn. 19.

21 Vgl. Wollenschläger (Anm. 18), Bd. 1, § 8 Rdn. 31; ähnlich Safferling, NStZ 2014, 545, 550; Burchard/Brodowski, StraFo 2010, 179, 182.

22 Wollenschläger (Anm. 18), Bd. 1, § 8 Rdn. 21. 
Grundfreiheiten, Systementscheidungen von Sekundärrechtsakten sowie dem Effektivitäts- und Loyalitätsgebot ${ }^{23}$.

Auch hinsichtlich der Einschränkung von Grundfreiheiten wird zutreffend darauf verwiesen, dass die Zulässigkeit ihrer Beschränkung und die hierbei anerkannten Gründe sich exklusiv nach Unionsrecht richten ${ }^{24}$. Ungleich mehr Schwierigkeiten bereitet die Fallgruppe der sog. unionsrechtlich determinierten Kontexte. Hier ist die Anwendbarkeit der GRC am wenigsten scharf konturiert. Wie eng und prägend bzw. determinierend der Bezug zu unionsrechtlichen Vorschriften sein muss, ist noch nicht abschließend geklärt. Das bloße Bestehen einer Regelungskompetenz hat der EuGH - entgegen GA Sharpston ${ }^{25}$ - bislang nicht genügen lassen ${ }^{26}$. Schon vor Inkrafttreten der GRC hatte der EuGH in der Rs. Annibaldi das Bestehen von hinreichend konkreten unionsrechtlichen Vorgaben zur Voraussetzung für die Anwendung von Unionsgrundrechten gemacht ${ }^{27}$. Diese Rechtsprechung soll auch bei der Auslegung von Art. 51 GRC Beachtung finden ${ }^{28}$. Der EuGH hat im Anschluss an deren Leitlinien zuletzt präzisierend darauf abgestellt ${ }^{29}$, ob mit der in Rede stehenden nationalen Regelung (oder Maßnahme) die Durchführung einer Bestimmung des Unionsrechts bezweckt wird, welchen Charakter die Regelung hat und ob mit ihr nicht andere als die unter das Unionsrecht fallenden Ziele verfolgt werden ${ }^{30}$, selbst wenn sie

23 Wollenschläger (Anm. 18), Bd. 1, § 8 Rdn. 21; ähnlich Ohler, NVwZ 2013, 1433: Trotz des Gestaltungsfreiraums (bei Umsetzungsspielräumen oder Beschränkung der Pflichten auf Mindestharmonisierungsschritte) bewege sich die Regelungstätigkeit des Staates im sachlichen Anwendungsbereich des Unionsrechtsakts.

24 Wollenschläger, EuZW 2014, 577, 579; a. A. aufgrund der Deutung der unionsrechtlich eingeräumten Gestaltungsspielräume als autonomer, nicht determinierter Bereich, Kingreen, in: Calliess/Ruffert (Anm. 9), Art. 51 Rdn. 17.

25 GA Sharpston, Schlussanträge v. 30. 09. 2010 in der Rs. C-34/09 (Ruiz Zambrano), Slg. 2011, I1177 , Rdn. $163 \mathrm{ff}$.

26 Auch der specific interest-Ansatz des Generalanwalts Villalón in seinen Schlussanträgen v. 12. 06. 2012 in der Rs. C-617/10 (Åkerberg Fransson), Rdn. 40 f. konnte sich nicht durchsetzen.

27 EuGH, Urteil v. 18. 12. 1997, Rs. C-309/96 (Annibaldi), Slg. 1997, I-7493, Rdn. 13 ff.

28 Die Erläuterungen des Präsidiums des Konvents zu Art. 51 GRC nehmen ausdrücklich auf dieses Urteil Bezug.

29 EuGH, Rs. C-206/13 (Siragusa), Rdn. 23, 25. In dieser Sache ging es um die Entfernung von Bauten, die nach italienischem Landschaftsschutzrecht unerlaubt errichtet worden waren.

30 In EuGH, Rs. C-483/09, C-1/10 (Gueye und Sànchez), Slg. 2011, I-08263, Rdn. 51 war die Relevanz des Rahmenbeschlusses zur Stellung des Opfers in Strafverfahren für die Entscheidung der streitgegenständlichen Rechtsfragen verneint worden, weil der Rechtsakt einen anderen Regelungszweck (Behandlung von Opfern im Strafverfahren und effektiver Rechtszugang für Opfer) hatte und sich nicht zu den entscheidungserheblichen materiell-strafrechtlichen Fragen und der Art und Höhe von Sanktionen verhielt. 
das Unionsrecht mittelbar beeinflussen kann, sowie ferner darauf, ob es eine Regelung des Unionsrechts gibt, die für diesen Bereich spezifisch ist oder ihn beeinflussen kann. Relevant sei insofern auch, ob die Nichtanwendung der Unionsgrundrechte den Vorrang, die Einheit und die Wirksamkeit von Unionsrecht beeinträchtigten würde ${ }^{31}$. Daran gemessen bliebe die GRC unanwendbar, wenn die unionsrechtlichen Vorschriften in dem betreffenden Sachbereich den Mitgliedstaaten keine Verpflichtungen im Hinblick auf den im Ausgangsverfahren fraglichen Sachverhalt auferlegen ${ }^{32}$. Lediglich (mögliche) mittelbare Wechselwirkungen mit Sachpolitiken der Union (z.B. das Funktionieren einer gemeinsamen Agrarmarktorganisation ${ }^{33}$ ) vermögen keinen hinreichenden $\mathrm{Zu}$ sammenhang zu begründen. Es bedarf somit also zumindest eines Bezugs des mitgliedstaatlichen Handelns $\mathrm{zu}$ konkreten unionsrechtlichen Vorschriften ${ }^{34}$. Hierfür kann nach jüngerer EuGH-Rechtsprechung aber schon die primärrechtliche Pflicht „zur wirksamen Ahndung von die finanziellen Interessen der Union gefährdenden Verhaltensweisen“ aus Art. 325 AEUV ausreichen ${ }^{35}$.

\section{Verhältnis zu nationalen Grundrechten}

Das Bundesverfassungsgericht hat vor diesem Hintergrund schon frühzeitig zu verstehen gegeben, dass es eine zu weit gehende unitarisierende Expansion der Unionsgrundrechte als Ultra-vires-Akt bewerten würde. Nicht jeder lose Bezugspunkt oder jede indirekte Wechselbezüglichkeit könne genügen. Andernfalls sei die Wahrung eines gehaltvollen nationalen Grundrechtsschutzes gefährdet. Infolgedessen muss eine hinreichend enge Verbindung des mitgliedstaatlichen Handelns zum Unionsrecht nachgewiesen werden, um die GRC zur Anwendung

$31 \mathrm{EuGH}$, Urteil v. 6. 3. 2014, Rs. C-206/13 (Siragusa), Rdn. $31 \mathrm{f}$.

32 EuGH, Urteil v. 6. 3. 2014, Rs. C-206/13 (Siragusa), Rdn. 26.

33 EuGH, Urteil v. 6. 3. 2014, Rs. C-206/13 (Siragusa), Rdn. 29.

34 Z.B. wenn das Unionsrecht in nationalen Verfahren zu beachtende subjektive Rechte gewährt; Schaller, EuZW 2003, 666, 671f., Klagen vor mitgliedstaatlichen Gerichten zur Durchsetzung subjektiver Rechte des Gemeinschaftsrechts sind daher Durchführung des Gemeinschaftsrechts und unterliegen somit Bindung an Unionsgrundrechte, S. 672; ähnlich Frenz, Handbuch Europarecht, 2008, Band 4, Europäische Grundrechte, Rdn. 257.

35 EuGH, Rs. C-617/10 (Åkerberg Fransson), Rdn. 24ff. Dort ging es um Verstöße gegen Steuererklärungspflichten; dazu auch Safferling, NStZ 2014, 545, 548; siehe auch EuGH, Urteil v. 8. 9. 2015, Rs. C-105/14 (Taricco); sowie implizit EuGH, Urteil v. 5. 6. 2012, Rs. C-489/10 (Bonda); ausdrücklich zuvor GA Kokott, Schlussanträge v. 15. 12. 2011, Rs. C-489/10 (Bonda), Rdn. 18. f.; dort standen Flächenzahlungen im Rahmen der Gemeinsamen Agrarpolitik im Zentrum. 
gelangen zu lassen ${ }^{36}$. Es ist jedoch nicht ersichtlich, dass der EuGH diese Grenzen bisher überschritten hätte.

Sind die Anwendungsvoraussetzungen von Art. 51 GRC erfüllt, kommt aufgrund der Notwendigkeit der einheitlichen Rechtsanwendung als verbindlicher Grundrechtskatalog die GRC zum Zug und beansprucht grundsätzlich Vorrang gegenüber nationalen Grundrechten. Diese sind bei Anwendbarkeit der GRC aber nicht zwingend suspendiert, sondern bleiben im Einklang mit der Entscheidung des EuGH in der Rs. Åkerberg Fransson parallel anwendbar und können sogar weitergehenden Schutz gewähren, soweit Schutzgehalte resp. Schutzrichtung kongruent sind. Nationale Grundrechte können nach neuerer Auffassung des EuGH im Anwendungsbereich des Unionsrechts zumindest dann direkt zur Anwendung kommen, wenn „das Handeln eines Mitgliedstaats nicht vollständig durch das Unionsrecht bestimmt wird, [...] sofern durch diese Anwendung weder das Schutzniveau der Charta, wie sie vom Gerichtshof ausgelegt wird, noch der Vorrang, die Einheit und die Wirksamkeit des Unionsrechts beeinträchtigt werden.“" ${ }^{\text {37 }}$ Allerdings endet die parallele Anwendbarkeit gemäß der Melloni-Rechtsprechung dort, wo (namentlich bei kollidierenden Schutzgehalten) das Schutzniveau der Charta, wie sie vom Gerichtshof ausgelegt wird, oder Vorrang, Einheit und Wirksamkeit des Unionsrechts beeinträchtigt werden ${ }^{38}$. Damit können die nationalen Grundrechte gerade bei der Umsetzung und Durchführung von unionsrechtlichen Vorgaben sowie beim Handeln in unionsrechtlich determinierten Kontexten weiterhin eine wichtige Rolle spielen ${ }^{39}$.

Ein gutes Beispiel dafür ist die „EuHb II“-Entscheidung des Bundesverfassungsgerichts v. 15. 12. $2015^{40}$. Das OLG Düsseldorf hatte einen Europäischen Haftbefehl zu prüfen, mit dem die Generalstaatsanwaltschaft bei der Corte di Appello von Florenz um die Auslieferung zur Strafvollstreckung ersuchte. Dabei versäumte es das Oberlandesgericht im Zulässigkeitsverfahren trotz fundierter Einwände der gesuchten Person, eine sorgfältige Prüfung möglicher Versagungsgründe gem. IRG vorzunehmen. Der Betroffene war in Abwesenheit verurteilt worden und bemängelte, dass ihm im Falle der Auslieferung keine effektive Möglichkeit zur nachträglichen Überprüfung des Urteils in tatsächlicher und

36 BVerfGE, Urteil v. 24. 04. 2013, 1 BvR 1215/07, Rdn. 90; s.a. Britz, EuGRZ 2015, 275.

37 EuGH, Rs. C-617/10 (Åkerberg Fransson), Rdn. 29; EuGH, Rs. C-399/11 (Melloni), Rdn. 60; siehe auch Safferling, NStZ 2014, 545, $548 \mathrm{ff}$.

38 EuGH, Rs. C-399/11 (Melloni); dazu auch Franzius, ZäöRV 2015 383, 397 ff.

39 Wollenschläger (Anm. 18), Bd. 1, § 8 Rdn. 19; s.a. Franzius, ZäöRV 2015, 383, 394 ff.

40 BVerfG, Urteil v. 15. 12. 2015, 2 BvR 2735/14; dazu ausf. Brodowski, JR 2016, 415; Classen, Europarecht 2016, 304; Meyer, HRRS 2016, 332; Nettesheim, JZ 2016, 424; Sachs, JuS 2016, 373; Sauer, NJW 2016, 1134; Schönberger, JZ 2016, 422. 
rechtlicher Hinsicht offenstehen würde. Das OLG falsifizierte diese substantiierte Behauptung nicht, sondern berief sich auf den Grundsatz gegenseitiger Anerkennung (da nicht auszuschließen sei, dass das italienische Recht dem Betroffenen eine wirksame Wiederaufnahmemöglichkeit einräumt). Die italienischen Behörden hatten es ihrerseits versäumt, Zweifel mit einer wirksamen Zusicherung auszuräumen. Da das OLG Düsseldorf eine Vorlage zum EuGH nicht in Erwägung zog und ein ordentlicher Rechtsweg gegen Zustimmungsentscheidungen im Auslieferungsverfahren nicht besteht, war die Verfassungsbeschwerde der einzige Ausweg, um die Auslieferung zu verhindern. Das Bundesverfassungsgericht schloss die Schutzlücke und befand, dass die Zustimmung zur Auslieferung das Grundgesetz verletzte, weil das OLG seinen von Art. 1 Abs. 1 GG gebotenen Pflichten zur Prüfung der Vorbringen sowie zur Sicherstellung des erforderlichen Mindeststandards an Verfahrensrechten in Italien nicht nachgekommen war ${ }^{41}$. Hierbei handele es sich um eine aus der Menschenwürde und dem Schuldprinzip fließende, unerlässliche Voraussetzung zur Wahrung der Subjektstellung des Betroffenen.

Während die Entscheidung in der Sache sicherlich richtig ist und funktionell ein wichtiger Beitrag für einen umfassenden Grundrechtsschutz im Raum der Freiheit, der Sicherheit und des Rechts geleistet wird, hat der Weg, den das Bundesverfassungsgericht einschlägt, um die Anwendbarkeit nationaler Grundrechte $\mathrm{zu}$ begründen, nahezu einhellig Kritik erfahren ${ }^{42}$. Es versteht seine Prüfungskompetenz nicht als Fall der parallelen Anwendbarkeit nationaler Grundrechte bei grundsätzlich fortbestehendem Anwendungsvorrang des Unionsrechts, sondern präsentiert sie als prioritäre Pflicht zum Schutz der Verfassungsidentität; und damit als Grenze des Anwendungsvorrangs ${ }^{43}$. Diese Linie setzte das Bundesverfassungsgericht in einem weiteren Beschluss unbeirrt fort. Dort sah sich das Gericht mit der Frage konfrontiert, ob eine mögliche Unterschreitung der eigenen verfassungsrechtlichen Standards zum Schweigerecht in einem nach Überstellung im Vereinigten Königreich durchzuführenden Verfahren nicht nur ein Eingreifen, sondern ein Durchgreifen nationaler Grundrechte erfordere ${ }^{44}$, was man im einstweiligen Rechtsschutz nicht von vornherein ausschlieBen wollte.

41 BVerfG, Urteil v. 15. 12. 2015, 2 BvR 2735/14, Rdn. 113, 119, 123.

42 Brodowski, JR 2016, 415; Classen, Europarecht 2016, 304; Frank Meyer, HRRS 2016, 332; Nettesheim, JZ 2016, 424; Sachs, JuS 2016, 373; Sauer, NJW 2016, 1134; Schönberger, JZ 2016, 422.

43 BVerfG, Urteil v. 15. 12. 2015, 2 BvR 2735/14, Rdn. 34, 36; krit. Classen, Europarecht 2016, 304 , 311: „schädliche Überdramatisierung.

44 BVerfG, Beschluss v. 06. 05. 2016, 2 BvR 890/16; das Bundesverfassungsgericht ist aber später zurückgerudert und hat die Beschwerde nicht zur Entscheidung angenommen; BVerfG, Beschluss v. 06.09.2016, 2 BvR 890/16. 
Ungeachtet des Umstandes, dass eine Kollision zwischen grundsätzlich vorrangigem Unionsrecht und nationalem Verfassungsrecht (als Grundvoraussetzung für die Auslösung einer Identitätskontrolle) im ersten Fall eindeutig nicht vorlag $^{45}$ und im zweiten Fall nicht vertieft geprüft wurde ${ }^{46}$, bleibt festzuhalten, dass offenbar Uneinigkeit über das Vorgehen bei der Klärung des Verhältnisses zwischen europäischer und nationaler Grundrechtsebene herrscht.

Die Frage, wann eine anwendungsauslösende unionsrechtliche Determinierung besteht und wie weit diese im Einzelfall reicht, büßt dadurch aber nichts von ihrer zentralen Bedeutung ein. Als besondere Herausforderung für die Rechtsanwendung erweisen sich dabei mehrpolige Grundrechtsverhältnisse, denn mit der Berufung auf einen weiterreichenden nationalen grundrechtlichen Schutzgehalt kann die Unterschreitung des chartarechtlichen Schutzniveaus eines anderen Grundrechts verbunden sein ${ }^{47}$. Gerade im Strafrecht besteht eine multipolare Spannungslage zwischen Interessen der Allgemeinheit, des Beschuldigten und des (mutmaßlichen) Opfers. So kann ein erhöhtes Niveau von Opferschutzrechten die Möglichkeiten einer effektiven Verteidigung schmälern. Umgekehrt kann eine Erweiterung von Beschuldigtenrechten den Schutzbereich von Rechten Dritter schmälern, zu deren Realisierung die vom Täter verletzten Verhaltensnormen dienen sollten ${ }^{48}$. Eine erhebliche Rolle für die Auflösung dieser mitunter komplexen Spannungslagen wird dem zweiten Sperrkriterium der Vorrang- und Wirksamkeitsbeeinträchtigung zukommen, das bereits im Fall Melloni (und, wenngleich weniger gut sichtbar, im Fall Taricco ${ }^{49}$ ) zur Geltung kam.

45 Classen, Europarecht 2016, 304; 308f.; Frank Meyer, NJECL 7 (2016), S. 277, 283; Sauer, NJW 2016, 1134, 1135. Dies konstatiert auch das BVerfG an späterer Stelle, Urteil v. 15. 12. 2015, 2 BvR 2735/14, Rdn. 125.

46 Eine mögliche nachteilige Verwertung des Schweigens von Beschuldigten ist weder im RBEuHB noch in der Rspr. des EGMR als Ablehnungsgrund anerkannt. Über die GRC könnte sich allerdings ein darüber hinausgehender Schutz ergeben; vgl. knapp Frank Meyer, HRRS 2016, 332, 338.

47 Allg. Kirchhof, EuR 2014, 267, 268. Eine Spannungslage kann sich auch im Verhältnis zwischen EMRK und GRC im Kontext der Kohärenzklausel ergeben. Bei mehrpoligen Grundrechtsverhältnissen stellt sich auch dort die Frage, inwiefern die Gewährung eines erhöhten Schutzes nach der GRC der Mindestschutzgehalt hinsichtlich eines anderen Konventionsrechts nicht mehr gewahrt wäre, vgl. Cornils, Enzyklopädie Europarecht, 2014, Bd. 2, § 5 Rdn. 36; Ziegenhorn (Anm. 4), S. 233 ff., 240 ff., 257, der zwischen Chartarechten ohne konventionsrechtliche Entsprechung und Chartarechten, die in Bedeutung und Tragweite EMRK-Rechten (zumindest teilweise) entsprechen, unterscheidet, da für letztere die Sicherstellung der Kohärenz mit der EMRK die Behandlung der Mehrpoligkeit bestimme.

48 Vgl. z. B. den Fall Steffensen.

49 EuGH, Urteil v. 08. 09. 2015, Rs. C 105/14 (Taricco). 
Sehr weit ist die Wissenschaft bei der Konkretisierung und Operationalisierung der GRC-Bindungen bislang nicht gekommen ${ }^{50}$. Dies gilt insb. auch für das Straf- und Strafverfahrensrecht ${ }^{51}$. Dort scheint man sich der Problematik nur langsam bewusst zu werden. Es ist daher an der Zeit, eine Konkretisierung der allgemeinen Fallgruppen im strafrechtlichen Kontext zu versuchen.

\section{Anwendungsfallgruppen im Strafrecht}

\section{Unionsrechtliche Verpflichtungen zu Umsetzung oder Vollzug von Sekundärrecht}

Existieren unionsrechtliche Verpflichtungen zur Umsetzung oder zum Vollzug von Sekundärrecht, bestehen hinsichtlich der abstrakten Anwendbarkeit der GRC keine Unterschiede zwischen Bereichen ohne und mit Implementierungs- und Durchsetzungsspielräumen. Dennoch wird nachfolgend zwischen diesen Segmenten differenziert, da sich bei der Konkretisierung der Bindung auf späterer Stufe Unterschiede in Bezug auf die konkret anwendbaren Grundrechte und die Bindungstiefe ergeben können.

50 Mit unterschiedlichen Ansätzen siehe u. a. Masing, JZ 2015, 477, 481; Ohler, NVwZ 2013, 1433 , 1434; T. Kingreen, in: Calliess/Ruffert (Anm. 9), Art. 51 Rdn. 7; siehe auch Nusser, Die Bindung der Mitgliedstaaten an die Unionsgrundrechte, 2011, S. $9 \mathrm{ff}$.

51 Für die wenigen Versuche siehe Marguery, Modern Journal 20 (2013), S. 282: Unionskompetenz und Ausübung der Kompetenz lösen Bindung aus; Marguery bemüht sich dann, das Ausmaß der Bindung über Reichweite und Inhalte der strafrechtlichen EU-Kompetenzen im Raum der Freiheit, der Sicherheit und des Rechts zu klären, 288 ff.; Safferling, NStZ 2014, 545 f.; Jarass, NStZ 2012, 611; Nestler, HRRS 2013, 337; Risse, HRRS 2014, 93, 100 ff.; Rönnau/Wenger, GA 2013, 561, 569ff.; Stalberg, Zum Anwendungsbereich des Art. 50 der Charta der Grundrechte der Europäischen Union (ne bis in idem), Frankfurt a.M. 2013, behandelt die Thematik nur im Zusammenhang mit der Ne-bis-in-dem-Garantie des Art. 50 GRC. Er folgt bei der Anwendbarkeitsprüfung einem engen Ansatz, S. 53 ff.: Die rechtliche Beurteilung des maßgeblichen Sachverhalts müsse von einer Norm geprägt werden, die dem primären oder sekundären Unionsrecht angehöre, S. 69. Offenbar soll dafür eine europarechtliche Determinierung nationaler Straftatbestände nicht genügen, S. 68f., sodass die Verhängung einer Kriminalstrafe aufgrund eines harmonisierten nationalen Tatbestands nicht den Schutz von Art. 50 i. V.m. Art. 51 GRC auslösen könnte. Zu überzeugen vermag die dafür gegebene Begründung nicht. Eine kaum vertretbare Extremposition vertritt Eckstein, ZIS 2013, 220, 224: Nur unmittelbar wirkendes europäisches Straf- und Strafverfahrensrecht (das de lege lata freilich noch gar nicht existiert) könne von den Mitgliedstaaten i. S.v. Art. $51 \mathrm{GRC}$ als Unionsrecht durchgeführt werde. 


\section{a) Determinierter Umsetzungs- und Vollzugsbereich}

Der Umsetzungsbereich betrifft zunächst die sekundärrechtlichen Verpflichtungen zum Erlass von Mindestvorschriften im Straf- und Strafverfahrensrecht sowie im Rechtshilferecht. Darunter fallen die Verpflichtungen, eine Missachtung bestimmter unionsrechtlicher Vorschriften unter Strafe zu stellen (Art. 83 Abs. 1 und Abs. 2 AEUV, Art. 31 Abs. 1 lit. e EUV a. F., implied powers aus ex-EGV) $)^{52}$, gewisse (der Rechtsannäherung dienende) Mindestregelungen im materiellen Straf- und Sanktionenrecht zu verbürgen (Art. 83 Abs. 1 und Abs. 2 AEUV, Art. 31 Abs. 1 lit. e EUV a.F.), prozessrechtlichen Annäherungspflichten zu genügen (Art. 82 Abs. 2 AEUV) oder (soweit es sich um zwingende Vorgaben handelt) die Rechtsakte zur gegenseitigen Anerkennung in der Rechtshilfe zu implementieren (Art. 82 Abs. 1 AEUV). Konkrete Umsetzungspflichten können sich auch aus einem Zwang zur sog. Assimilierung als Ausfluss der allgemeinen Loyalitätspflicht ergeben ${ }^{53}$.

Dem Vollzugsbereich (agency situation) zugehörig sind die Sanktionierung der Verletzung nationaler Normen, die in Umsetzung von EU-Recht erlassen worden $\operatorname{sind}^{54}$, sowie die Sanktionierung der Verletzung von Normen, die vom Unionsrecht vorgegebenen Zielen dienen ${ }^{55}$. Voraussetzung für eine Bindung an die GRC ist in diesen Fällen aber, dass sich aus dem Unionsrecht eine Pflicht

52 Jarass, NStZ 2012, 611, 613; Eser, in: Jürgen Meyer (Anm. 6), Vorbemerkungen Titel VI Rn. 3; Zerbes/El-Ghazi, HRRS 2014, 209, 218; Nestler, HRRS 2013, 337, 342; als Auslöser kommen alle strafrechtlichen Rahmenbeschlüsse und Richtlinien in Betracht, die solche Pflichten enthalten; ihre Umsetzung kann auf unterschiedlichen Wegen erfolgen; z. B. § 264 Abs. 1, 7 Satz 1 Nr. 2; die unionsrechtlichen Rechtsgüter wurden mit Gesetz zu dem Übereinkommen vom 26. Juli 1995 über den Schutz der finanziellen Interessen der Europäischen Gemeinschaften [EG-Finanzschutzgesetz/EGFinSchG] direkt in den Tatbestand integriert. Andere Normen bedienen sich (insb. jedoch zur Assimilierung, siehe auch Anm. 53) sog. Gleichstellungsklauseln in den jeweiligen Tatbeständen zur Einbeziehung von Unionsrechtsgütern, Hecker, Europäisches Strafrecht, 5. Aufl. 2015, § 2 Rdn. 6 mit Beispielen; zu Blankettstrafnormen mit Rückverweisungsklauseln; Satzger, Internationales und Europäisches Strafrecht, 7. Aufl. 2015, § 9 Rdn. 72f.

53 Zur Assimilierung Heger, Enzyklopädie Europarecht, 2013, Bd. 9, §5 Rdn. 8 ff.; Hecker (Anm. 52), § 2 Rdn. 6; § 7 Rdn. 1 ff., 67 ff.

54 Gaede, Enzyklopädie Europarecht, 2013, Bd. 9, § 3 Rdn. 26 mit Beispiel des WpHG; Jarass, NStZ 2012, 611; Risse, HRRS 2014, 93, 110.

55 Lange, NVwZ 2014, 169; dies kann einerseits dort der Fall sein, wo auf eine positiv-rechtliche Umsetzung von sekundärrechtlichen Kriminalisierungs- und Annäherungsvorgaben verzichtet wird, weil sich eine Umsetzung bereits im Wege der europarechtskonformen Auslegung realisieren lässt; andererseits geht es hier um Fälle, in denen sich Kriminalisierungspflichten aus dem Loyalitätsprinzip ergeben; Beispiele bei Hecker (Anm. 52), § 10 Rdn. 65 ff.; Satzger (Anm. 52), § 9 Rdn. 96 ff.; Vormbaum, Schutz der Rechtsgüter von EU-Staaten durch das deutsche Strafrecht Zur europarechtskonformen Gestaltung und Auslegung von deutschen Straftatbeständen, 2005, S. 157. 
ergibt, nationale Durchsetzungsvorschriften mit Sanktionscharakter vorzusehen. Die GRC gelangt daher nicht zur Anwendung, wenn das zugrundeliegende (durchzusetzende) Fachrecht zwar bestimmte (unionsrechtlich umsetzungsbedürftige) materielle Aspekte regelt, das Unionsrecht jedoch keine auf diese materiellen Vorgaben bezogenen Sanktionierungspflichten formuliert oder die konkret verletzte Verhaltensnorm nicht unionsrechtlich festgelegt wurde ${ }^{56}$. Dies ist jeweils im Einzelfall zu prüfen. Schließlich zählt auch die Anwendung der Kooperationsvorschriften im Rechtshilferecht zu diesem Bereich ${ }^{57}$.

\section{b) Spielräume im Umsetzungs- und Vollzugsbereich}

Dort, wo das Unionsrecht den Mitgliedstaaten Spielräume bei Umsetzung oder Vollzug belässt, aber den rechtlichen Rahmen für die Realisierung und nachfolgende Ermessensentscheidungen absteckt, wäre die GRC gleichwohl anwendbar. Von dieser Bindung betroffen wären auf Ebene der Umsetzung ${ }^{58}$ die Ausgestaltung einer allgemeinen Sanktionierungspflicht als Strafnorm ${ }^{59}$, die Festlegung von Sanktionshöhen innerhalb der Harmonisierungsspielräume, die Widmung einer nationalen Norm zur Erfüllung (auch) unionsrechtlicher Ziele ${ }^{60}$, aber auch die Implementierung der Rechtsakte zur gegenseitigen Anerkennung in der Rechtshilfe, soweit deren Inhalte nicht ohnehin zwingend sind ${ }^{61}$. Auf Vollzugs-

56 Vgl. EuGH, Rs. C-144/95 (Maurin), Slg. 1996, I-2909, Rdn. 11f. Im entschiedenen Fall traf das Gemeinschaftsrecht Regelungen insb. zur Lebensmittelkennzeichnung, ohne aber Sanktionspflichten festzuschreiben. Das nationale Verfahren betraf dagegen Vorschriften über den Verkauf, die allein auf inländischer Regulierung beruhten und deshalb keinen Bezug zum Gemeinschaftsrecht herzustellen vermochten.

57 Billing, EuCLR 2012, 77, 83: Erlass eines EuHb und die Ausführungsbeschlüsse durch Justizbehörden im ausstellenden und vollstreckenden Staat.

58 Jarass, NStZ 2012, 611, 613.

59 Die Verpflichtung, bestimmte Verhaltensweisen sanktionsrechtlich zu bekämpfen, genügt; EuGH, Rs. C-405/10 (Garenfeld), wonach die GRC ,von den Mitgliedstaaten v. a. dann zu beachten ist, wenn sie die Missachtung unionsrechtlicher Vorschriften unter Strafe stellen“; Gaede (Anm. 54), Bd. 9, § 3 Rdn. 26; Risse, HRRS 2014, 93, 101.

60 Jarass, NStZ 2012, 611, 613 unter Hinweis auf die Verhaltensnormen im Umwelt- oder Gesundheitsrecht; dies geschieht v.a. durch Einbeziehung unionsrechtlicher Verhaltensnormen und Schutzgüter im Wege der Auslegung in Erfüllung einer allgemeinen Sanktionierungspflicht; vgl. Vormbaum (Anm. 55), S. 116 ff.; Satzger (Anm. 52), § 9 Rdn. 96 ff.

61 Vgl. z.B. Art. 13 Abs. 4 S. 2 RB EuHB. Bezüglich der Entscheidung über fakultative Versagungsgründe wie z.B. Art. 4, 4a RB EuHB wird bisweilen argumentiert, dass dem Gesetzgeber darin kein Ermessen eingeräumt wird, sondern nach dem Wortlaut nur den vollstreckenden Justizbehörden. Der Gesetzgeber wäre vielmehr unionsrechtlich verpflichtet, eine hinreichende 
ebene greift die Bindung an die GRC wiederum bei der Sanktionierung von Verstößen gegen die EU-rechtlich induzierten Strafnormen, soweit diesbezüglich Ermessensspielräume bestehen, bei der Auslegung nationaler (materiell-rechtlicher und prozess-rechtlicher) Vorschriften anhand von Bezugsnormen aus dem Unionsrecht ${ }^{62}$ sowie der (nicht vollständig determinierten) Anwendung der Kooperationsvorschriften im Rechtshilferecht ${ }^{63}$.

\section{Unionsrechtlich geprägte Fallgestaltungen}

Auf dem Gebiet des Europäischen Strafrechts kommt es für die Anwendbarkeit der GRC jedoch nicht allein darauf an, ob ein Lebenssachverhalt ein technisches Umsetzungs- oder Durchführungselement aufweist. Vielmehr genügt es, wenn der Sachverhalt durch einen hinreichend engen Bezug zum Unionsrecht geprägt ist. In der Praxis dürften sich freilich diverse Überschneidungen zwischen der ersten und der zweiten Anwendungsfallgruppe zeigen.

In Betracht kommen vor allem Konstellationen, in denen man auf verpflichtende oder sonst auslegungsrelevante Sekundärrechte (insb. Richtlinien) ${ }^{64}$ stößt, ohne sich bereits im Bereich des indirekten Unionsvollzugs zu bewegen. Die Auslegungsrelevanz oder Beeinflussung kann sich dabei gerade aus der Notwendigkeit ergeben, Vorrang, Einheit und Wirksamkeit von Unionsrecht zu wahren.

gesetzliche Basis für die Entscheidung der Justizbehörden zu schaffen; zur Diskussion vgl. Suominen, The Principle of Mutual Recognition in Cooperation in Criminal Matters, Cambridge 2011, S. 304 ff. Dem wäre aber entgegenzuhalten, dass die Versagungsgründe derart grundrechtswesentliche Fragen betreffen, dass sie vom Gesetzgeber entschieden bzw. entscheidend vorgeprägt werden müssen. Weder Systematik noch Regelungszweck des Rahmenbeschlusses stehen dem entgegen. Es würde die Einheitlichkeit und Effektivität der Rechtsanwendung gerade gefährden, wenn eine Justizbehörde über alle Versagungsgründe in jedem Fall selbst entscheiden können müsste. Umgekehrt könnte man sich auf den Standpunkt stellen, dass eine Ausgestaltung als zwingender Versagungsgrund durch den Gesetzgeber gegenüber dem justiziellen Ermessen eine (unzulässige) Einschränkung der Vollstreckbarkeit von Europäischen Haftbefehlen bewirkt. 62 Wenn Strafnorm sich auf unionsrechtlich geregelte Materie bezieht, Lange, NVwZ 2014, 169; siehe z. B. EuGH, Rs. C-405/10 (Garenfeld): Gegenstand der Entscheidung war die Auslegung einer umweltrechtlichen Verordnung, auf die sich die nationale Blankettstrafnorm des $\S 326$ Abs. 2 Nr. 1 StGB bezog. Betroffenes Charta-Recht war Art. 49 GRC. Eine GRC-auslösende Beachtungspflicht setzt für diese Kategorie von Fällen schon mit Ablauf der Umsetzungsfrist ein; auch dann, wenn die Umsetzung ausbleibt.

63 Billing, EuCLR 2012, 77, 83.

64 Jeweils zu prüfen wäre mithin, ob im Regelungsumfeld ein möglicherweise relevanter Unionsrechtsakt besteht und ob sich aus diesem direkt oder mittelbar über Art. 4 Abs. 3 EUV oder Art. 325 Abs. 1 AEUV konkrete Vorgaben für die Rechtsanwendung ergeben. 
In einem so gelagerten Fall wäre die GRC auch dann anwendbar, wenn eine (unionsrechtlich) auslegungsbedürftige nationale Norm nicht zur Implementierung von Unionsrecht geschaffen oder ihr dezidiert gewidmet wurde. Denn die in solchen Fällen erforderliche unionsrechtskonforme Normanwendung wäre dann als Maßnahme zur Durchführung des Unionsrechts i.S. d. Art. 291 AEUV zu qualifizieren ${ }^{65}$.

Bezüge dieser Art ergeben sich immer dort, wo das nationale Strafverfahren Rechtsbereiche berührt, in denen harmonisiertes Unionsrecht existiert. Derartige Regelungen aus Richtlinien und Verordnungen können dann als materiellrechtliche Bezugsnormen oder Limitierungen bei der Tatbestandsauslegung entscheidungserheblich werden (unionsrechtskonforme Auslegung mit ausgestaltender und begrenzender Wirkung ${ }^{66}$. An dieser Stelle ist beispielsweise an die Neutralisierung nationaler Sanktionsvorschriften durch Sekundärrecht zu denken ${ }^{67}$. Dieser Anwendungsbereich weist aufgrund seiner Begründungslogik eine große Nähe zu einer weiteren, ebenfalls Art. 51 Abs. 1 GRC unterfallenden Konstellation auf, in der ein Unionsrechtsakt i. V.m. Loyalitätspflicht und Effektivitätsgrund$\mathrm{sat}^{68}$ eine spezifische Verpflichtung hervorbringt oder zumindest eine Kanalisierung strafrechtlicher und strafprozessualer Normanwendung bewirkt ${ }^{69}$. Dies kann

65 Die GRC-Bindung griffe freilich auch bei Übersehen der Auslegungsbedürftigkeit einer nationalen Norm.

66 Z.B. das harmonisierte EU-Umweltrecht, Hecker (Anm. 52), § 2 Rdn. 7; siehe § 330d Abs. 2 Nr. 1 StGB.

67 EuGH, Rs. C-148/78 (Ratti), Slg. 1979, 1629; EuGH, Rs. 271/82 (Ministère public/Auer), Slg. 1983, 2727; EuGH Rs. 16/83 (Prantl), Slg. 1984, 1299; Hecker (Anm. 52), § 9 Rdn. 24 ff., wo Fälle der sekundärrechtlichen und primärrechtlichen Neutralisierung nebeneinander dargestellt werden; vorliegend wird der letztgenannte Fall bei den Grundfreiheiten behandelt.

68 Allg. zur Wirkung des Rechtsprinzips der Effektivität bei Rechtsetzung und Rechtsanwendung Hilf/Hörmann, Festschrift für Tomuschat, S. 913, 940 f., $942 \mathrm{ff}$.

69 Frank Meyer, in: v. d. Groeben/Schwarze/Hatje (Hrsg.), Europäisches Unionsrecht, 7. Aufl. 2015, Vor Art. 82ff. AEUV Rdn. 37. Der exakte Grad der Bindung und der Ermessenslenkung soll nach Ohler mit dem Maß der unionsrechtlichen Determininierung korrelieren, Ohler, NVwZ 2013, 1433, 1437; Ohler spricht sich damit für variable Lösungen aus, die sich ein Beispiel an der Rechtsfigur des margin of appreciation des EGMR nehmen sollte; zu bedenken wäre jedoch, ob nicht aus der anders ausgerichteten Methodik des Unionsrechts folgt, dass im Verhältnis EUMitgliedstaat die Grenzen eines margin of appreciation nicht notwendig enger zu ziehen wären, weil das Fachrecht und das mit ihm verbundene Integrationsprogramm eine bestimmte, ggf. strengere Lesart fordern. Der supranationale Charakter der Rechtsmaterie verlangt gerade nach dem Schutz ihrer Einheitlichkeit; nicht zuletzt, um deren Wirksamkeit sicherzustellen. Wie weit ein margin of appreciation reichen dürfte bzw. durch den EuGH zu akzeptieren wäre, wird in der Regel vom Einzelfall abhängen. Grundrechtsdogmatisch müsste diese Problematik wohl beim Schutzbereich oder beim Vorliegen einer Beeinträchtigung, die auf der Ausübung supranationaler Hoheitsgewalt beruht, zur Sprache kommen. 
der Fall sein, wenn sich Kriminalisierungspflichten aus dem Loyalitätsprinzip ergeben $^{70}$. Gleiches gilt, wo das Erfordernis erwächst, auf Verstöße gegen qualitativ analoge unionsrechtliche Regelungen in gleicher Weise zu reagieren wie im nationalen Strafrecht (sog. Assimilierung $\left.{ }^{71}\right)^{72}$. In diesen Konstellationen (aber auch bei jenen unter I.) ist auch eine Ausstrahlung auf Entscheidungen über Einstellung, Anklage oder Verständigungen vorstellbar, weil die wirksame Durchsetzung des Unionsrechts eine effektive Strafverfolgung und ggf. Anklageerhebung gebieten und deshalb die üblichen nationalrechtlichen Entscheidungsparameter modifizieren oder gar verdrängen könnte ${ }^{73}$.

Ferner kann die Existenz eines auf Unionsrecht basierenden Verfahrensrechts innerhalb des Verfahrens (z. B. Beschuldigtenrechte aus der Richtlinie 2010/64/ EU des Europäischen Parlaments und des Rates vom 20. 10. 2010 über das Recht auf Dolmetschleistungen und Übersetzungen im Strafverfahren oder Opferrechte aus Richtlinie 2012/29/EU des Europäischen Parlaments und des Rates vom 25. Oktober 2012 über Mindeststandards für die Rechte, die Unterstützung und den Schutz von Opfern von Straftaten sowie zur Ersetzung des Rahmenbeschlusses 2001/220/JI) genügen, um einen hinreichenden Bezug zum Unionsrecht herzustellen $^{74}$. Dieser brächte aber nicht die Charta insgesamt und für das gesamte Verfahren zur Anwendung, sondern nur insoweit, als dies für die Auslegung bzw. die spezifische Anwendung erforderlich ist ${ }^{75}$. Beispielsweise ist die Reichweite des Rechts auf Übersetzung wesentlicher Unterlagen in Art. 3 RL 2010/64 auch davon abhängig, welche Unterlagen nach dem allgemeinen Recht auf ein faires Verfahren als wesentlich einzustufen $\operatorname{sind}^{76}$. Für die Auslegung von Opferrechten

70 Hecker (Anm. 52), § 7 Rdn. 24 ff.; Satzger (Anm. 52), § 9 Rdn. 26 f.

71 Hecker (Anm. 52), § 7 Rdn. 16 ff. mit Beispielen im deutschen Strafrecht unterteilt nach Umsetzungstechniken, Rdn. $68 \mathrm{ff}$.

72 Dieser Wirkungsmechanismus ist weiterhin aktiv, Asp, Festschrift für Frisch, S. 1389, 1398 f.

73 Vgl. Frank Meyer, in: v. d. Groeben/Schwarze/Hatje (Anm. 69), Art. 83 Rdn. 4, 60.

74 EuGH, Rs. C-483/09, C-1/10, (Gueye u. Sànchez), Slg. 2011, I-08263, Rdn. 55, 63ff.; s. aber auch Rn. 69 zur Veranschaulichung der Grenzen der Bindung bei dieser Fallgruppe; EuGH, Urteil v. 16. 6. 2005, Rs. C-105/03 (Pupino), Slg. 2005, I-5285.

75 Vgl. EuGH, Rs. 404/07 (Katz), Slg. 2008, I-07607, Rdn. 48, 50: Der Fall betraf Art. 2 und 3 des Rahmenbeschlusses über Opferrechte, die dahin auszulegen waren, dass sie ein nationales Gericht zwar nicht dazu verpflichten, dem Opfer einer Straftat im Rahmen eines Ersatzprivatklageverfahrens wie des im Ausgangsverfahren in Rede stehenden zu gestatten, als Zeuge gehört zu werden. Soweit eine solche Möglichkeit nicht besteht, müsste es dem Opfer aber gestattet werden, eine Aussage zu machen, die als Beweismittel berücksichtigt werden kann. Andernfalls würde Art. 3 Abs. 1 ein Großteil seiner praktischen Wirksamkeit genommen und gegen die Verpflichtungen aus Art. 2 Abs. 1 verstoßen.

76 Vgl. EuGH, Urteil v. 15. 10. 2015, Rs. C-216/14 (Covaci), Rdn. 39. Dort wird interessanterweise direkt auf die EMRK Bezug genommen. Danach schließt das in Art. 3 Abs. 1 und 2 der Richtlinie 
auf Entschädigung oder Schutz (Art. 16, 18 ff. RL 2012/29) können dagegen materielle Rechte wie der Schutz von Leib, Leben und Privatsphäre oder Grundfreiheiten eine Rolle spielen ${ }^{77}$.

Auch das Bestehen primärrechtlicher Pflichten zum sanktionsrechtlichen Vorgehen gegen Normverstöße wie in Art. 325 AEUV hat bereits wiederholt zur Anwendung der Charta geführt ${ }^{78}$. Zumindest bei hinreichend schweren Steuerdelikten, welche auch die finanziellen Interessen der EU berühren, geht der EuGH davon aus, dass die entsprechenden nationalen Strafvorschriften auch der Durchführung von Unionsrecht dienen ${ }^{79}$. Ähnlich verhält es sich bei der betrügerischen Erschleichung von Agrarsubventionen ${ }^{80}$. In derartigen Fällen wird mit der Normanwendung supranationale Hoheitsgewalt ausgeübt, sodass es nur konsequent erscheint, wenn auch die GRC zur Anwendung gelangt ${ }^{81}$. Vor dem Hintergrund des Systems der Eigenmittelfinanzierung der EU kommt Art. 325 AEUV damit eine außergewöhnlich weitreichende Schnittstellenfunktion zu. Alle Regelungen, die finanzielle Interessen der Union berühren und mittelbar (d.h. über Art. 325 AEUV)

2010/64 vorgesehene Recht auf Übersetzung grundsätzlich nicht die schriftliche Übersetzung eines Schriftstücks wie des Einspruchs gegen einen Strafbefehl ein, den die betreffende Person in einer Sprache verfasst hat, deren sie mächtig ist, die aber nicht die Verfahrenssprache ist.

77 RL 2012/29/EU des Europäischen Parlaments und des Rates vom 25. Oktober 2012 über Mindeststandards für die Rechte, die Unterstützung und den Schutz von Opfern von Straftaten sowie zur Ersetzung des Rahmenbeschlusses 2001/220/JI, ABl. 2012 L 315, S. 57; Bock, ZIS 2013, 201, $205 \mathrm{ff}$.

78 EuGH, Rs. C-617/10 (Åkerberg Fransson); EuGH, Urteil v. 08. 09. 2015, Rs. C-105/14 (Taricco), Rdn. 37; GA Kokott, Schlussanträge v. 15. 12. 2011, Rs. C-489/10 (Bonda). Den materiellen Hintergrund bildet das System der Eigenmittelfinanzierung der EU; dazu auch Rönnau/Wenger, GA 2013, 561, 570. Da diese auch Einnahmen umfassen, die sich aus der Anwendung eines einheitlichen Satzes auf die durch Richtlinien festgelegte einheitliche Mehrwertsteuer-Eigenmittelbemessungsgrundlage ergeben, betreffen Mängel bei der Erhebung der Mehrwertsteuer in den Mitgliedstaaten zugleich den Unionshaushalt. Nationale Sanktionsvorschriften schützen damit auch automatisch rechtlich geschützte Unionsinteressen mit und dienen mithin der Durchführung von Unionsrecht. Art. 325 AEUV begründet insofern einen Unionsbezug sowohl für die Normgebung als auch für den Vollzug. Gleiches lässt sich für nationale Vorschriften sagen, die eine missbräuchliche Beantragung von Stützungsmitteln der Gemeinsamen Agrarpolitik ahnden.

79 Insoweit seien die Mitgliedstaaten zu strafrechtlichem Vorgehen verpflichtet, EuGH, Urteil v. 08. 09. 2015, Rs. C 105/14 (Taricco), Rdn. 39, was auch die strafrechtlichen Garantien zur Anwendung bringt.

80 GA Kokott, Schlussanträge v. 15. 12. 2011, Rs. C-489/10 (Bonda), Rdn. $17 \mathrm{f}$.

81 So auch GA Kokott, Schlussanträge v. 15. 12. 2011, Rs. C-489/10 (Bonda), Rdn. 19f.; Vervaele, Utrecht Law Review 9 (2013), S. 211, 224: Dient eine Maßnahme (direkt oder indirekt) dem effektiven und gleichwertigen Schutz von Unionsinteressen, muss dabei auch effektiver und gleichwertiger Schutz der Unionsgrundrechte gewahrt sein. 
Sanktionspflichten auslösen, können einen hinreichenden unionsrechtlichen Bezug herstellen.

Demgegenüber kann die allgemeine Verpflichtung aus Art. 3 EUV, einen Raum der Freiheit, der Sicherheit und des Rechts zu bilden, als solche nicht genügen ${ }^{82}$. Diese Zielbestimmung statuiert einen allgemeinen Gestaltungsauftrag, dessen Ausführung erst dann messbare Rechtswirkungen zeitigt, wenn die Gesetzgebungsorgane tatsächlich im Rahmen des Kompetenzkatalogs des Art. 67 AEUV konkrete Implementierungsschritte ergreifen. Anderenfalls geriete die Bindung noch expansiver als bei dem vom EuGH bereits abgelehnten abstrakten Abstellen auf das bloße Vorhandensein von unionsrechtlichen Kompetenzen.

\section{Einschränkung von Grundfreiheiten}

Die Bindungskategorie der Einschränkung von Grundfreiheiten mag für Strafrechtler ungewohnt erscheinen. Sie hat aber auch für das Strafrecht eine nicht als gering zu veranschlagende Bedeutung. $\mathrm{Zu}$ ihr gehören z. B. die hochgradig praxisrelevanten Fälle der Kriminalisierung von grundfreiheitlich geschütztem Verhalten oder des Unterbleibens grundfreiheitskonformer Auslegung bei der Anwendung von Strafnormen (sog. Neutralisierung, Art. 34 ff. AEUV) ${ }^{83}$.

Zudem können Sanktionen gerade wegen ihrer Auswirkung auf die Ausübung von Grundfreiheiten unverhältnismäßig geraten ${ }^{84}$. Die Grundrechte spielen in diesem Zusammenhang eine ambivalente Rolle. Sie fungieren einerseits

82 Vgl. allerdings Burchard/Brodowski, StraFo 2010, 179, 182 (dort Fn. 27) zu der Überlegung, dass aufgrund der zunehmenden Integriertheit und Koordiniertheit der nationalen Strafverfolgung und ihrer befriedenden Wirkung für den Raum insgesamt der Anwendungsbereich der Justizgrundrechte zumindest für diejenigen strafrechtlichen Sachverhalte eröffnet sein soll, die wenigstens zwei Mitgliedstaaten betreffen. Dem ist zu entgegnen, dass alleine der Umstand, dass zwei Staaten betroffen sind und kooperieren, diese Interaktion noch nicht zu einer Form supranationaler Hoheitsgewalt macht. Die Union hat keine allgemeine Befriedungsfunktion für den RFSR, sodass die (nicht zu bestreitende) Befriedungsrelevanz mitgliedstaatlichen Verhaltens diesem nicht automatisch einen Unionsbezug verleiht bzw. die Qualität als supranationale Hoheitsgewalt zuwachsen lässt. Eine Grundrechtsrelevanz kann sich freilich aus dem Gegenstand und dem Instrumentarium der Kooperation ergeben, wenn diese zur Gewährleistung des RFSR geschaffen wurden oder eine sonstige unionsrechtliche Determiniertheit festzustellen ist.

83 EuGH, Rs. 8/74 (Dassonville), Slg. 1974, 837; EuGH, Rs. C-159/90 (Society for the Protection of Unborn Children Ireland), Slg. 1991, I-4685; EuGH, Rs. C-234/01 (Gambelli), NJW 2004, 139; EuGH, Rs. C-338/04 (Placanica), Slg. 2007, I-1891; EuGH, Rs. C-409/06 (Winner Wetten), NVwZ 2010, 1419; EuGH (GK), Rs. C- 316/07 (Markus Stoß), NVwZ 2010, 1409; EuGH, Rs. C-46/08 (Carmen Media), NVwZ 2010, 1422; EuGH(GK), Urteil v. 8. 9. 2009, Rs. C-42/07, Slg. 2009, I-7633.

84 EuGH, Urteil v. 19. 01. 1999, Rs. C-348/96 (Donatella Calfa), Slg. 1999, I-11. 
(grundfreiheitsflankierend) als Schranken-Schranken ${ }^{85}$. Andererseits können sie den Mitgliedstaaten zur Rechtfertigung des Eingriffs dienen, wenn Unionsgrundrechte mit der Beschränkung von Grundfreiheiten geschützt werden sollen ${ }^{86}$. Strafbewehrte Ausübungsverbote können sich mithin (ggf. auch über den Schutz entsprechender nationaler Garantien ${ }^{87}$ hinausgehend) auch auf den Schutz von GRC-Rechten stützen ${ }^{88}$.

Weitere Einschränkungen können insb. in Bezug auf die Personenfreizügigkeit in grenzübergreifenden Konstellationen auftreten ${ }^{89}$. Das klassische Anwendungsbeispiel der Beeinträchtigung von Grundfreiheiten durch strafprozessuale Maßnahmen ist das Verbot der Doppelverfolgung (ne bis in idem), das nunmehr grundrechtlich in Art. 50 GRC selbständig verankert ist, aber weiterhin wesentlich durch die freizügigkeitsgetriebene Auslegung von Art. 54 SDÜ geprägt ist ${ }^{90}$. Weniger eindeutig ist noch, ob mitgliedstaatliche Jurisdiktionsabsprachen und Koordinierungsentscheidungen im Rahmen von Eurojust oder Europol Grundfreiheiten rechtlich unmittelbar betreffen ${ }^{91}$. Hierzu wäre ein Nachweis vonnöten, dass derartige Abreden einen abschreckenden Effekt in Bezug auf die Ausübung von Grundfreiheiten haben.

$\mathrm{Zu}$ denken ist aber auch an mögliche Diskriminierungen von Freizügigkeitsberechtigten (Art. 18 AEUV) bei der Anwendung nationaler Prozessrechtsvorschriften $^{92}$. Prägnante Beispiele sind die Ungleichbehandlung bei Opferrechten

85 Kahl/Schwind, EuR 2014, 170, 179f.; Wollenschläger (Anm. 18), Bd. 1, § 8 Rdn. 25. Z. B. wenn die Maßnahme auch das Recht auf Familien- und Privatleben betrifft.

86 EuGH, Urteil v. 12. 6. 2003, Rs. C-112/00 (Schmidberger), Slg. 2003, I-5659, Rdn. 69 ff., 74.; Schorkopf (Anm. 6), Bd. 2, § 3 Rdn. 23; Kahl/Schwind, EuR 2014, 170, 172ff., arbeiten präzisierend heraus, dass die Rechtsprechung des EuGH verschiedene Ansätze zur Reichweite der Schrankenfunktion (Konkordanz, Hierarchie, Drittwirkung) erkennen lässt.

87 Deren Schutz wird in derartigen Fällen in der Regel der Ausgangspunkt für die nationalen Instanzen sein.

88 Denkbar wären z. B. Schutzansprüche aus dem Recht auf Sicherheit.

89 Muir/van der Mei, The Citizenship Dimension of the Area of Freedom, Security and Justice, in: Luchtman (Hrsg.), Choice of Forum in Cooperation Against Financial Crime, 2013, 123-142.

90 Radtke, Enzyklopädie Europarecht, 2013, Bd. 9, § 12 Rdn. 3f.; Frank Meyer, in: v. d. Groeben/ Schwarze/Hatje (Anm. 69), Art. 82 Rdn. 29.

91 Allg. zur Relevanz von Diskriminierungsverbot und Grundfreiheiten für Jurisdiktionsfragen; Böse, in: Böse/Frank Meyer/Schneider (Hrsg.), Conflicts of Jurisdiction in Criminal Matters in the European Union, Vol. II, 2014, $44 \mathrm{ff}$.

92 Insb. bei Opferrechten, vgl. EuGH, Rs. 186/87 (Cowan/Trésor public), Slg. 1989, 195 (Art. 18, 56 AEUV); EuGH, Rs. C-274/96 (Bickel u. Franz), Slg. 1998, I-7637 (Art. 18, 21 AEUV); EuGH, Rs. C164/07 (Wood), Slg. 2008, I-4143 (Art. 18, 21 AEUV); aber auch beim Auslieferungsschutz; dort kommt es nach dem IRG zu einer Ungleichbehandlung von Deutschen und Bürgern anderer Mitgliedstaaten bei der Anwendung von Überstellungshindernissen; für Freizügigkeitsberechtig- 
oder Überstellungshindernisse im Auslieferungsrecht. Konkret berührte ChartaRechte könnten in einer solchen Konstellation im Legislativprozess oder anlässlich der konkreten Normanwendung bei der Verhältnismäßigkeitsprüfung Berücksichtigung finden. Beeinträchtigungen der Personenfreizügigkeit können auch von nationalen Regelungen ausgehen, die (ohne diskriminierenden Charakter) davon abschrecken, von der Freizügigkeit Gebrauch zu machen ${ }^{93}$. Einen derartigen chilling effect wird man allerdings nicht vorschnell unterstellen dürfen. Um als ernsthaftes Hindernis erachtet $\mathrm{zu}$ werden, müssten die Regelungen wohl eine Schärfe erreichen, die sich nicht mehr mit dem europäischen ordre public vereinbaren ließe. Ein potenzieller Kandidat hierfür könnten nationale Regelungen zur Vorratsdatenspeicherung sein, die der EuGH auf Unionsebene für unvereinbar mit den Unionsgrundrechten hält ${ }^{94}$. Möglicherweise resultiert der von GA Villalòn ${ }^{95}$ diagnostizierte chilling effect aber nicht aus isolierten einzelstaatlichen Regelungen, sondern erst aus der flächendeckenden, unionsweiten Einführung.

Im Anschluss an die Ruiz-Zambrano-Rechtsprechung des EuGH ist ferner zu erörtern, ob Beeinträchtigungen der Unionsbürgerschaft auch in rein internen Konstellationen (innerhalb eines Mitgliedstaats) vorstellbar sind (und damit zur Anwendbarkeit von Unionsrecht und mithin der GRC führen) ${ }^{96}$. Dies erschiene in Anlehnung an das öffentlich-rechtliche Schrifttum nur dann begründbar, wenn fundamentale Grundwerte verletzt sind, die an den Wesenskern der Unionsbür-

te mit dauerhaftem Aufenthaltsrecht muss die Gleichbehandlung sichergestellt sein, Frank Meyer, in: Ambos/König/Rackow, Rechtshilfe in Strafsachen, 2015, Art. 83b IRG, Rdn. 976 unter Bezugnahme auf EuGH, 5. 9. 2012, Rs. C-42/11 (Lopes Da Silva Jorge); EuGH, Rs. C-123/08 (Wolzenburg), Slg. 2009, I-9621. Böse sieht ferner in der Ausübung extraterritorialer Jurisdiktion grundsätzlich eine Beschränkung der allgemeinen Freizügigkeit, die sich nur in Bezug auf das Auswirkungsprinzip (effects principle), das Realprinzip und die stellvertretende Strafrechtspflege rechtfertigen lässt, in: Böse/Frank Meyer/Schneider (Anm. 91), S. 43, 73 ff., 104f. Beim passiven Personalitätsprinzip, S. 51, 58, sowie beim aktiven Personalitätsprinzip, S. $69 \mathrm{ff}$. , macht er dagegen unzulässige Ungleichbehandlungen aus.

93 Siehe Beispiel bei Muir/van der Mei (Anm. 89), S. 123, 129; bezugnehmend auf GA Jacobs, Schlussanträge v. 09. 12. 1992 in der Rs. 168/91 (Konstantinidis), Slg. 1993, I-1191, Rdn. 48.

94 EuGH, Rs. C-293/12 u. C-594/12 (Digital Rights Ireland u. Kärntner Landesregierung), Rdn. $57 \mathrm{ff}$.

95 GA Villalón, Schlussanträge vom 12. Dezember 2013 in der Rs. C-293/12 (Digital Rights Ireland, Ltd.), Rdn. 52.

96 Die zu „Ruiz Zambrano“ analoge strafrechtliche Sachverhaltskonstellation wäre die Auslieferung eines Nicht-Unionsbürgers ohne dauerhaftes Aufenthaltsrecht mit minderjährigen, im Inland dauerhaft wohnhaften Familienmitgliedern, die Unionsbürger sind. Mit der Argumentation des EuGH ließe sich auch hier ein Eingriff plausibel begründen. Bei hinreichend schweren Straftaten wäre dieser aber wohl zu rechtfertigen. 
gerschaft rühren und das Unionsbürgerrecht damit letztlich seiner Substanz berauben ${ }^{97}$. In den Sinn kämen hier massive Kriminalisierungen von Meinungsäußerungen oder weitere Expansionen der Präventions-/Sicherheitsgesetzgebung, mit denen die Strafbarkeit noch weiter in das Vorfeld messbarer Rechtsgutsbeeinträchtigungen verschoben wird. Derartigen Ausweitungsvorschlägen wird entgegengehalten, dass sie keine Rücksicht auf das Verfassungs- und Kompetenzgefüge der EU nehmen ${ }^{98}$. Ohnehin wäre für Grundrechtsverletzungen der genannten Qualität im europäischen Grundrechts-Mehrebenensystem eigentlich der EGMR zuständig. Unionsbürger gewännen mit der Doppelung von Grundrechten nichts, zumal ihnen kein eigener Rechtsweg zum EuGH offenstehen würde ${ }^{99}$.

Eindeutig ist hingegen, dass die (drohende) Strafverfolgung und Strafverhängung bzw. eine spätere Freiheitsentziehung in anderen Mitgliedstaaten als solche das Unionsrecht unberührt lassen, soweit die abgeurteilte Tat keinen anderweitigen Bezug zum Unionsrecht aufweist ${ }^{100}$. Ebenfalls nicht $\mathrm{zu}$ einer Freizügigkeitsbeeinträchtigung führt die Aufspaltung des Rechtschutzes zwischen Anordnungsstaat und Vollstreckungsstaat bei der strafrechtlichen Zusammenarbeit nach Maßgabe des Grundsatzes der gegenseitigen Anerkennung ${ }^{101}$.

Mit diesem ersten Schritt ist gleichwohl nur die grundsätzliche Anwendbarkeit der Grundrechtecharta geklärt. Offen sind mit dem Umfang der Bindung, ihrem Konkurrenzverhältnis zu Vorschriften des Sekundärrechts und

97 V. Bogdandy/Kottmann/Antpöhler/Dickschen/Hentrei/Smrkolj, ZaöRV 72 (2012), S. 45, 66f. Werte i.S.v. Art. 2 EUV in einer Intensität i.S.v. Art. 7 Abs. 2 EUV; Muir/van der Mei, The Citizenship Dimension of the Area of Freedom, Security and Justice, in: Luchtman (Hrsg.), Choice of Forum in Cooperation Against Financial Crime, 2013, S. 123, $137 \mathrm{ff}$.

98 Muir/van der Mei (Anm. 89), S. 123, 139f.; es droht zugleich eine Diskriminierung von NichtUnionsbürgern.

99 Kritisch auch Muir/van der Mei (Anm. 89), S. 123, $141 \mathrm{f}$.

100 EuGH, Urteil v. 29. 05. 1997, Rs. C-299/95 (Kremzow): Dass eine Freiheitsstrafe die Freizügigkeit über Ländergrenzen hinweg behindert, ist nur eine mittelbare, unbeabsichtigte Nebenfolge, eine Begleiterscheinung der Strafe. Die Verhängung einer Freiheitsstrafe wegen einer Tat, die für sich genommen keinen Bezug zum Unionsrecht hat, kann daher nicht am EU-Recht gemessen werden.

101 Vgl. EGMR, Urteil v. 04. 05. 2010-56588/07 (Stapleton). Dort wird der gespaltene Rechtsschutz allerdings nur unter dem Blickwinkel des fairen Verfahrens gem. Art. 6 EMRK geprüft. Soweit sich jüngst Aufweichungen einer strikten Trennung bei der Fairnessbewertung insofern andeuten, als der verfahrensführende Staat bestimmte Rechtsverstöße im Vollstreckungsstaat auch auf ihre Auswirkungen auf die Fairness des konkret geführten Strafverfahrens prüfen muss (vgl. EGMR, Urteil v. 27. 10. 2011 - 25303/08 [Stojkovic], NJW 2012, 3709, Rdn. 51f.), berührte dies Grundfreiheiten erst dann, wenn eine drohende Nichtbeachtung dieser Standards spürbare Auswirkungen auf die Ausübung der Freizügigkeit hätte. Das ist nur schwer vorstellbar. 
ihrem Konkurrenzverhältnis zu nationalen Grundrechten noch einige Fragen, die für die Anwendungspraxis als elementar erscheinen. Zum Umfang der Bindung ist vorrangig zu klären, welche Grundrechte überhaupt in den einzelnen Fallgruppen zur Anwendung kommen können und wie weit diese Bindung reicht.

\section{Konkretisierungsversuche}

Lässt man den Blick über die Anwendungsfallgruppen schweifen, ergeben sich einige typische Anwendungssituationen, in denen zugleich weiterer Konkretisierungsbedarf hinsichtlich der Reichweite der Grundrechtsbindung herrscht. Von besonderer Bedeutung sind nationale Gesetzgebungsverfahren zur Umsetzung von Unionsrecht, die Durchführung von Rechtshilfeverfahren sowie die Verfahrensdurchführung zur Strafverfolgung von Verletzungen EU-induzierter oder europäisierter Strafnormen. Bei dieser Fallgruppe wird der Schwerpunkt auf die GRC-Bindung bei der Anwendung mitgliedstaatlichen Verfahrensrechts gelegt. Hierbei wird weiter zwischen den Konstellationen des Erlasses nationaler Verwaltungs- und Verfahrensvorschriften zur Durchführung von Unionsrecht, der punktuellen Gewährleistung einzelner unionsrechtlich vorgegebener Verfahrensrechte, der Neutralisierung nationaler Sanktionsvorschriften durch Sekundärrecht oder Grundfreiheiten sowie verfahrensbeendenden Entscheidungen und Strafzumessung differenziert.

\section{Nationale Gesetzgebungsverfahren zur Umsetzung von Unionsrecht}

Bei der Normsetzung greifen sowohl die Garantien aus Art. 49 GRC als auch die jeweils betroffenen materiellen Grundrechte und Grundfreiheiten. Dabei entsprechen die Bindungen aus Art. 49 GRC zunächst einmal dem Acquis der EMRK; Art. 49 Abs. 1 und 2 GRC entsprechen Art. 7 EMRK $^{102}$. Davon umfasst sind die Gesetzmäßigkeit von Straftaten und Strafen (inkl. ihrer diversen Einzelgewährleistungen) und das Rückwirkungsverbot ${ }^{103}$. Ohne internationales Vorbild ist die Einführung eines Grundsatzes verhältnismäßiger Strafen als Sonderfall der all-

102 Eser, in: Jürgen Meyer (Anm. 6) Art. 49 Rdn. 2.

103 Jarass (Anm. 12), Art. 49 Rdn. 1, 3; Eser, in: Jürgen Meyer (Anm. 6), Art. 49 Rdn. 1, 12ff.; str. ist, ob Gewohnheitsrecht genügen kann (so Eser, in: Jürgen Meyer [Anm. 6], Art. 49 Rdn. 13, 39) oder nicht (Jarass [Anm. 12], Art. 49 Rdn. 10 unter Hinweis auf Art. 52, GRC). 
gemeinen Verhältnismäßigkeit ${ }^{104}$. In vielen Staaten wird dieser Grundsatz auch verfassungsrechtlich abgesichert sein. Die Besonderheit in der hier zu behandelnden Konstellation liegt darin, dass es für die Bewertung der Proportionalität auf legislativer Ebene maßgeblich auf die unionsrechtlichen Vorgaben zu Unrechtsgehalt und Sanktionsbedürfnis ankommt ${ }^{105}$. Zusätzlich wird der Gesetzgeber rechtliche Regelungen zur Gerichtszuständigkeit und zu den Verjährungsfristen treffen müssen, soweit sich diese nicht bereits aus dem allgemeinen Gerichtsverfassungsrecht resp. allgemeinem Verjährungsrecht ergeben ${ }^{106}$. Diese Notwendigkeit folgt aus der jüngeren Rechtsprechung des EGMR, die über Art. 52 Abs. 3 i.V.m. Art. 47 GRC materiell verbindlich einfließt, wobei sie allerdings keine ins Detail gehenden Vorgaben oktroyiert.

Inwiefern zusätzlich materielle Unionsgrundrechte und Grundfreiheiten ins Spiel kommen, hängt wesentlich vom Regelungsgegenstand ab. Jedenfalls wird der Gesetzgeber sich bei Anwendbarkeit der GRC intensiv mit den potenziell einschlägigen Gewährleistungen auseinanderzusetzen haben. $\mathrm{Zu}$ wahren sind die materiellen Grundrechtsgrenzen, die schon aus der EMRK bekannt sind, namentlich das Recht auf Schutz des Privatlebens (Art. 8 EMRK, Art. 7 GRC), die Meinungsäußerungsfreiheit (Art. 10 EMRK, Art. 11 GRC), das Recht auf Leben (Art. 2 EMRK, Art. 2 GRC), das Recht auf körperliche Unversehrtheit (Art. 2 EMRK, Art. 3 GRC), der Schutz personenbezogener Daten (Art. 8 GRC), die Gedanken-, Gewissens- und Religionsfreiheit (Art. 10 GRC) und das Eigentumsrecht (Art. 1 ZP EMRK, Art. 17 GRC; z. B. bei Einziehungsregelungen oder bei gesetzgeberischen Bestrebungen zur Einführung von sog. non-conviction-based forfeitures). Als unionsrechtliche Besonderheit kommen eine ausdrückliche Menschenwürdegarantie (Art. 1 GRC) und das Gebot der Nichtdiskriminierung aus Art. 21 GRC hinzu, das eine Schlechterstellung von Freizügigkeitsberechtigten gegenüber den eigenen Staatsbürgern bei der Ausgestaltung straf- und strafverfahrensrechtlicher Vorschriften grundsätzlich untersagt ${ }^{107}$. Während die vorgenannten Rechte vor-

104 Jarass (Anm. 12), Art. 49 Rdn. 5; Eser, in: Jürgen Meyer (Anm. 6), Art. 49 Rdn. 5, 36. Als Normquelle werden Rechtsstaatsprinzip und Menschenwürde (Jarass [Anm. 12], Art. 49 Rdn. 3) sowie Menschenwürde i.V.m. allgemeinem Persönlichkeitsrecht und Rechtsstaatsprinzip (Eser, in: Jürgen Meyer [Anm. 6], Art. 49 Rdn. 36) benannt.

105 Diese Parameter sind dem operativen Teil der Sekundärrechtsakte sowie deren Begründung zu entnehmen; vgl. EuGH, Rs. C-262/99 (Louloudakis), Slg. 2001, I-5547 Rn. 67, 71.

106 EGMR, Urteil v. 23. 01. 2013 - 42931/10 (Camilleri); EGMR, Urteil v. 22. 6. 2000 - 32492/96 u. a. (Coëme u. a.); EGMR, Urteil v. 09. 01. 2013 - 21722/11 (Volkov).

107 Die neuen $\S \S 49$ Abs. 3 und 54a IRG bevorzugen beispielsweise einseitig deutsche Staatsangehörige. Im Unterschied zu den Fällen „Wolzenburg“ und „Lopes“ befanden sich die benachteiligten Ausländer zum Entscheidungszeitpunkt aber gerade auf dem Gebiet des diskriminierenden Staates. 
nehmlich die Tatbestandsseite betreffen, setzen insb. der Schutz gegen Folter, unmenschliche Behandlung und unmenschliches Strafen (Art. 3 EMRK, Art. 4 GRC) und das Recht auf Freiheit und Sicherheit (Art. 5 EMRK, Art. 6 GRC) Maßstäbe für zulässige Strafarten und -höhen sowie Vollzugsregimes ${ }^{108}$.

Bei der Sicherstellung materieller GRC-Konformität wird es primär, aber nicht ausschließlich, auf deren Abwehrfunktion ankommen. Denkbar ist jedoch auch, dass aus diversen GRC-Garantien positive Schutzpflichten erwachsen, auf die der nationale Gesetzgeber zu reagieren hat, indem er die gebotenen Vorkehrungen (und ggf. rechtlichen Ausgestaltungen) triff $\mathrm{t}^{109}$. In diesem Zusammenhang wird auch der Spielraum für eine primäre (soweit die GRC keine korrespondierenden Rechte enthält) oder parallele Berücksichtigung nationaler Grundrechte zu klären sein. Auch dies muss im Einzelfall geleistet werden, weil sich nur in der konkreten Regelungssituation ermessen lassen wird, ob und inwiefern Vorrang, Einheitlichkeit oder Wirksamkeit des Unionsrechts für Geltungskonflikte sorgen können. In dieser Hinsicht erweist es sich als praktisches Handicap, dass im Zuge nationaler Normgebungsverfahren keine (präventiven) Vorlagemöglichkeiten zum EuGH verfügbar sind, mit denen sich eine frühzeitige Klärung erreichen ließe.

\section{Rechtshilfeverfahren}

Die Rechtshilfeverfahren haben durch Rahmenbeschlüsse und Richtlinien bereits eine massive Annäherung erfahren. In diesem Umfang sind bei der Durchführung auch die Unionsgrundrechte $\mathrm{zu}$ wahren. Die wirkliche Schwierigkeit besteht in der Praxis jedoch nicht darin, die Geltung der GRC zu begründen, sondern darin, zum einen die Grundrechtsrelevanz einzelner Kooperationsformen genau $\mathrm{zu}$ taxieren und zum anderen eine etwaige Sperrwirkung des Sekundärrechts zu berücksichtigen. Der EuGH hat wiederholt betont, dass der Grundrechtsschutz, den die einschlägigen Sekundärrechtsakte gewährleisten, grundsätzlich abschließend und ausreichend ist und es daher nur ausnahmsweise angeht, sich im Rahmen der sekundärrechtlich regulierten strafrechtlichen Zusammenarbeit direkt auf die Grundrechtecharta $\mathrm{zu}$ berufen ${ }^{110}$, um

$108 \mathrm{Zu}$ den materiellen Grenzen supranationaler Rechtsetzung Frank Meyer, Strafrechtsgenese in internationalen Organisationen, 2012, S. $752 \mathrm{ff}$.

109 Die Schutzpflichtdogmatik in der GRC harrt allerdings noch ihrer ernsthaften Entfaltung; Breuer, Enzyklopädie Europarecht, 2014, Bd. 2, § 7 Rdn. 27; Borowsky, in: Jürgen Meyer (Anm. 1), Art. 51 Rdn. 31.

110 Frank Meyer, in: Ambos/König/Rackow (Hrsg.), Rechtshilferecht in Strafsachen, 2015, § 79 Rdn. $807 \mathrm{ff}$. 
darüber ungeschriebene Versagungsgründe herzuleiten oder die gesetzliche Einführung besonderer Kooperationseinschränkungen auf einfach-rechtlicher Ebene zu rechtfertigen. Zwar ist der EuGH mit der Leitentscheidung „Aranyosi“ von seiner bisherigen, vermeintlich kompromisslosen Linie abgerückt, indem er es zugelassen hat, aus dem Verbot der unmenschlichen Behandlung in Art. 4 GRC ein ungeschriebenes Kooperationshindernis abzuleiten ${ }^{111}$. Doch handelt es sich trotz des in grundsätzlicher Hinsicht richtungweisenden Charakters der Entscheidung um eine isolierte Konstellation, sodass nicht ohne Weiteres erkennbar ist, für welche sonstigen Fälle der Rückgriff auf die GRC nunmehr eröffnet ist. Denn der EuGH sah bewusst davon ab, Art. 1 Abs. 3 RB-EuHb zu einem allgemeinen Grundrechtsvorbehalt aufzuwerten. Die Schweigerechtsproblematik vor dem Bundesverfassungsgericht deutet an, dass man es mit weit mehr potenziellen Anwendungsfällen zu tun haben könnte als bislang gedacht; zumal der EuGH im „Aranyosi“-Urteil zu erkennen gab, dass Kooperationspflichten nicht erst beim Auftreten systemischer Mängel suspendiert sein können $^{112}$. Die aktuellen Verfahren vor dem Bundesverfassungsgericht und diversen Oberlandesgerichten lenken die Aufmerksamkeit zudem darauf ${ }^{113}$, dass je nach Sachlage neben der GRC auch nationale Grundrechtsstandards anzulegen und durchzusetzen sein können.

Neuere Instrumente wie die RL-EEA sehen dagegen bereits Quasi-Experimentierklauseln vor, die es den Mitgliedstaaten gestatten, bei der Implementierung und Durchführung von Maßnahmen des Sekundärrechts stets die Einhaltung grundrechtlicher Verbürgungen gewährleisten und auf neue Herausforderungen reagieren $\mathrm{zu}$ können ${ }^{114}$.

Neben zwingenden Vorgaben zur Annäherung des Rechtshilfeverfahrens gewähren die Sekundärrechtsakte zur Rechtshilfe auch optionale Gestaltungsmöglichkeiten, deren Nutzung im nationalen Ermessen steht. Dieser Schritt orientiert sich zwar primär an nationalen Verfassungsrechten und Rechtshilfestrukturen $^{115}$. Es dürfen jedoch keine Kollisionslagen gegenüber GRC-Rechten

111 EuGH, Urteil v. 05. 04. 2016 (Aranyosi u. Căldăraru), Rs. C-404/15 u. C-659/15 (PPU), ECLI: EU:C:2016:198, Rdn. 88; zu den Inhalten vgl. Besprechungen bei Meyer, JZ 2016, 621 ff.; Brodowski, JR 2016, 415, 429ff; Reinbacher/Wendel, EuGRZ 2016, 333, 337 ff.

112 Verlangt ist aber der Nachweis, dass der Mangel die betroffene Person individuell und unmittelbar betrifft; EuGH, Urteil v. 05. 04. 2016 (Aranyosi u. Căldăraru), Rs. C-404/15 u. C-659/15 (PPU), ECLI:EU:C:2016:198, Rdn. 89.

113 BVerfG, Urteil v. 15. 12. 2015, 2 BvR 2735/14; OLG Bremen - 1 Ausl. A 3/15, Vorlagebeschluss vom 23. Juli 2015.

114 Vgl. Art. 11 Abs. 1 lit. f RL-EEA: Versagung bei Unvereinbarkeit der Vollstreckung mit europäischen Grundrechten; vgl. auch Art. 31 Abs. 2 Proposal for a Council Regulation on the establishment of the European Public Prosecutor's Office, Rats.-Dok. 15100/15. 
herbeigeführt werden. Denn auch hier gilt wegen der Einbettung des Spielraums (z. B. bei fakultativen Versagungsgründen) in das Unionsrecht, dass die Unionsgrundrechte grundsätzlich anwendbar sind.

\section{a) Bestimmung grundrechtlicher Schutzbedürfnisse}

Im Bereich der Durchführung der Rechtshilfe besteht die erste Herausforderung somit darin, überhaupt den Anwendungsbedarf für Unionsgrundrechte zu erkennen. Hierzu ist Grundvoraussetzung, dass die Justizakteure (in Deutschland v. a. Generalstaatsanwaltschaften und Oberlandesgerichte) durchgängig kritisch die Grundrechtsrelevanz der verschiedenen Zusammenarbeitsformen reflektieren und ggf. auch neuartige Gefährdungslagen für die Grundrechte der Betroffenen wahrnehmen. ${ }^{116}$ Diese stellen sich nicht allein beim in der Diskussion omnipräsenten EU-Haftbefehl. Sie können sich ebenso aus der jeweiligen operationellen Umsetzung des Grundsatzes der gegenseitigen Anerkennung im Bereich der kleinen Rechtshilfe, ${ }^{117}$ beim Informationsaustausch oder beim Zusammenwirken mit supranationalen Agenturen ergeben. Bei der Identifizierung grundrechtlicher Schutzbedürfnisse müssen sich die Akteure die Notwendigkeit vergegenwärtigen, eine doppelte Neuausrichtung des Grundrechtsschutzes vorzunehmen, nämlich einerseits auf die neuen Rechtshilfemechanismen und andererseits auf die GRC. Diese Notwendigkeit soll nachstehend anhand des Europäischen Haftbefehls und einiger innovativerer Formen der Zusammenarbeit kursorisch exemplifiziert werden.

\section{(1) Beispiel „Europäischer Haftbefehl““}

Wie Art. 1 Abs. 3 RB-EuHB apodiktisch festhält, berührt der Rahmenbeschluss nicht die Pflicht, die Unionsgrundrechte und die allgemeinen Rechtsgrundsätze, wie sie in Art. 6 EUV niedergelegt sind, zu achten ${ }^{118}$. Der RB EuHB nimmt für sich

115 Vgl. BVerfGE 113, 273, 308 zum ersten EuHb-Gesetz.

116 Zum EuHb Bachmaier, NJECL 6 (2015), S. 505, 513ff.; (mit besonderem Bezug zur deutschen Praxis) Böse/Wahl, in: Albers/Beauvais/Bohnert/Langbroek/Renier/Wahl (Hrsg.), Towards a common evaluation framework to assess mutual trust in the field of EU, 2013, S. 212, 226ff., 232ff.; Frank Meyer, in: Ambos/König/Rackow (Anm. 110), Vor §§ $78 \mathrm{ff}$. Rdn. 780 f.; Schomburg, in: Breitenmoser/Gless/Lagodny (Hrsg.), Schengen und Dublin in der Praxis, 2015, S. $221 \mathrm{ff}$.; Report with Recommendations to the Commission on the Review of the European Arrest Warrant (2013/2109 (INL)) of the Committee on Civil Liberties, Justice and Home Affairs v. 28. 01. 2014.

117 Dort, wo neue Instrumente eine allgemeine Grundrechtsklausel vorsehen, müssen mögliche Anwendungsfälle substantiiert werden. 
zwar in Anspruch, dass er grundrechtsschützende Zulässigkeitsvoraussetzungen und Versagungsgründe unionsweit einheitlich regelt. Wie der Fall „Aranyosi“ zeigt, sind dabei jedoch nicht alle nach der EMRK anerkannten Kooperationshindernisse aufgegriffen worden. Daher wäre künftig stärker als bisher in Überstellungsfällen zu problematisieren, ob sich eine Schutzlücke im RB-EuHB auftut, die mit Hilfe der GRC zu füllen wäre. So hatte das OLG Bremen dem EuGH wegen der teils desolaten Zustände in ungarischen Haftanstalten (die bereits vom EGMR $^{119}$ und vom CPT gerügt worden waren) vorbildlich die Frage vorgelegt, ob „Art. 1 Abs. 3 des Rahmenbeschluss des Rates vom 13. 06. 2002 über den Europäischen Haftbefehl und die Übergabeverfahren zwischen den Mitgliedstaaten (2002/584/JI) so auszulegen [ist], dass eine Auslieferung zum Zwecke der Strafverfolgung unzulässig ist, wenn gewichtige Anhaltspunkte dafür bestehen, dass die Haftbedingungen im Ausstellungsmitgliedstaat die Grundrechte der betroffenen Person und die allgemeinen Rechtsgrundsätze, wie sie in Artikel 6 des Vertrages über die Europäische Union niedergelegt sind, verletzen, oder [ob er] so auszulegen [ist], dass der Vollstreckungsstaat in diesen Fällen die Entscheidung über die Zulässigkeit einer Auslieferung von einer Zusicherung der Einhaltung von Haftbedingungen abhängig machen kann oder muss?"120. Ein vergleichbares Schutzbedürfnis kann sich einstellen, wenn es im Ausstellungsstaat gravierende Fairnessverstöße gab bzw. zu geben droht, wofür zuletzt auch das Beispiel der nachteiligen Schlussfolgerungen aus Schweigen diskutiert wurde.

118 Der EuGH hat bereits die Vereinbarkeit des RB EuHB mit dem Legalitätsprinzip (EuGH, Urteil v. 03. 05. 2007, Rs. C-303/05, (Advocaten voor de Wereld), Slg. 2007, I-3633) sowie von Art. $4 \mathrm{a}$ Abs. 1 des Rahmenbeschlusses 2002/584 mit Art. 47 und 48 Abs. 2 GRC (EuGH, Rs. C-399/11 (Melloni), Rdn. 49 ff., 53) festgestellt. Gewiss ist dabei zutreffend, dass das Gesetzlichkeitsprinzip primär auf nationaler Ebene zu wahren ist. Indessen wird kritisiert, dass der EuGH mit seiner rein nationalen Deutung der Grundrechte die Gelegenheit hat verstreichen lassen, dem Legalitätsprinzip auch eine gefährdungsangepasste transnationale Relevanz zu verleihen, vgl. hierzu Hüttemann, Principles and Perspectives of European Criminal Procedure, Florenz 2012, S. $210 \mathrm{ff}$. In der Sache geht es freilich weniger um eine Erweiterung der Legalitätspflichten des ersuchenden Mitgliedstaats analog zur Stojkovic-Rspr. des EGMR als vielmehr um die Frage, welche Vorgaben auf Unionsebene (insb. zur beiderseitigen Strafbarkeit) wie genau geregelt werden müssten, damit die Unionsregelung ihre Ziele erreicht und zugleich Menschenrechte achtet, insb. eine EUweit verlässliche und kohärente Anwendung des Ausnahmekatalogs gewährleistet. Mit dem klassischen Gesetzlichkeitsprinzip hat dies indessen nur noch am Rande zu tun. Im Vordergrund stehen die Schutzzwecke der zu regelnden Auslieferungsvoraussetzungen und -hindernisse.

119 EGMR, Urteil v. 10. 03. 2015, Beschwerde Nr. 14097/12, 45135/12, 73712/12, 34001/13, 44055/ 13 (Varga) u. a./Ungarn.

120 OLG Bremen, 1 Ausl. A 3/15, Vorlagebeschluss v. 23. 06. 2015 sowie 1 Ausl A 23/15, Vorlagebeschluss v. 08. 12. 2015. 
Hinzu kommen neue, womöglich ursprünglich gar nicht bedachte kooperationsintrinsische Neben- und Folgewirkungen, welche aus der praktischen Funktionsweise des Überstellungssystems resultieren. Die erleichterte Verfügbarkeit potenzieller Täter hat sich nämlich in einem stark erhöhten Gebrauch des Instrumentariums niedergeschlagen, der in nicht wenigen Fällen Zweifel an der Verhältnismäßigkeit aufkommen lässt ${ }^{121}$, weshalb sich sogar die Kommission dazu aufgerufen fühlte, auf die Einhaltung dieses Rechtsgrundsatzes zu drängen $^{122}$. Der Europäische Haftbefehl wird nicht nur in einzelnen Staaten für Bagatellen missbraucht, sondern vielfach auch als Vorführhaftbefehl zur Ermöglichung einer Befragung des Betroffenen im ausstellenden Staat zweckentfremdet, ohne dass zuvor ein ernsthafter Versuch zur Aufenthaltsermittlung und Ladung unternommen würde. Es stellt sich daher die berechtigte Frage, wie sich ein besserer Schutz gegen exzessive und zweckwidrige Ersuchen erreichen lässt ${ }^{123}$. $\mathrm{Zu}$ den nicht bedachten Problemen gehören ferner Länge und Bedingungen der Untersuchungshaft im ausstellenden Staat, da Überstellungsgesuche mitunter weit vor Anklagereife ausgestellt werden ${ }^{124}$. Umso wichtiger werden damit für den Betroffenen im Umkehrschluss die Möglichkeiten einer effektiven Rechtswahrnehmung, um derartigen Härten möglichst präventiv zu begegnen. Der Unionsgesetzgeber hat hier mittlerweile mit der Richtlinie über das Recht auf Zugang zu einem Rechtsbeistand in Strafverfahren und in Verfahren zur Vollstreckung des Europäischen Haftbefehls (sowie über das Recht auf Benachrichtigung eines Dritten bei Freiheitsentzug und das Recht auf Kommunikation mit Dritten und mit Konsularbehörden während des Freiheitsentzugs) nachgebessert. Deren Art. 10 gewährt nunmehr im Falle der Festnahme das Recht auf einen Anwalt im vollstreckenden Staat. $\mathrm{Zu}$ dessen Unterstützung genießt der Betroffene auch das Recht auf einen Rechtsbeistand im Ausstellungsmitgliedstaat (vgl. Art. 10 Abs. 4). Damit ist ein erster Schritt zur effektiven Rechtswahrnehmung in grenzüberschreitend-integrierten Strafverfahren getan. Sie krankt aber weiterhin daran, dass es (noch) an einer einheitlichen Regelung zur Pro-

121 Thomas, ERA Forum 2013, 585, 587; Frank Meyer, in: Ambos/König/Rackow (Anm. 110), Vor $\S \S 78$ ff. Rdn. 780; Schomburg/Lagodny/Schallmoser, Enzyklopädie Europarecht, 2013, Bd. 9, § 13 Rdn. 110; Xanthopoulou, NJECL 6 (2015), S. 32, 47.

$122 \operatorname{KOM}(2011) 175$ endg., Bl. 9.

123 Vertreter des Schrifttums fordern u.a., dass ein europäischen Haftbefehl nicht mehr allein durch Staatsanwälte (wie in vielen Ländern möglich), sondern nur nach Prüfung durch ein unabhängiges Gericht erlassen werden darf, Schomburg, in: Breitenmoser/Gless/Lagodny (Anm. 116), S. 221, $230 \mathrm{f}$. Die zuständige Stelle im vollstreckenden Staat müsse sich sonst auf die Darstellung des zugrundeliegenden nationalen Haftbefehls durch den ausländischen Staatsanwalt verlassen, S. 233.

124 Thomas, ERA Forum 2013, 585, 588. 
zesskostenhilfe fehlt ${ }^{125}$ und die abstrakte Rechtsgewährung dadurch ausgehöhlt wird, und dies obwohl Art. 47 Abs. 3 GRC mittlerweile einen Anspruch auf Prozesskostenhilfe auch außerhalb von Strafverfahren im technischen Sinn garantiert ${ }^{126}$. Uneinig ist man sich auf europäischer Ebene in diesem Zusammenhang auch darüber, ob nicht eine notwendige Verbeistandung indiziert ist, um den gewachsenen Anforderungen an eine effektive Rechtswahrnehmung Genüge zu tun.

Ebenfalls nicht einheitlich geregelt sind zentrale Fragen wie der Aktenzugang im Ausstellungsstaat ${ }^{127}$ und weitere wichtige Fragen der Zuständigkeit und Prüfungspflichten für einzelne Rügen des Betroffenen ${ }^{128}$. Unklar ist zudem, ob bzw. unter welchen Voraussetzungen nationale Versagungsentscheidungen ${ }^{129}$ (zum Schutz der Freizügigkeit und des Rechts auf Achtung des Privat- und Familienlebens) unionsweit anzuerkennen wären, also Sperrwirkung entfalten, und wie diese ggf. unionsweit publik zu machen wären. Denn bei einem im SIS II eingestellten Haftbefehl bestünde sonst weiterhin das frappante Risiko, in den übrigen Mitgliedstaaten erneut festgenommen und einem Überstellungsverfahren ausgesetzt $\mathrm{zu}$ werden. Hiervon zu unterscheiden sind Konstellationen, in denen die Einhaltung der Grundrechte bei der Anwendung ausdrücklich geregelter Versagungshindernisse (z.B. Abwesenheitsentscheidungen ${ }^{130}$, ne bis in idem) im

125 Vgl. Vorschlag für eine Richtlinie über vorläufige Prozesskostenhilfe für Verdächtige oder Beschuldigte, denen die Freiheit entzogen ist, sowie über Prozesskostenhilfe in Verfahren zur Vollstreckung eines Europäischen Haftbefehls, KOM (2013) 824 endg.

126 Die Reichweite der Garantie ist freilich ihrerseits davon abhängig, was zur Gewährleistung eines effektiven Zugangs zu einem Gericht in Bezug auf das jeweils betroffene Recht (dessen Bestimmung wiederum von der mitgliedstaatlichen Sicht determiniert wird) für erforderlich gehalten wird.

127 Mansell, EuCLR 2012, 36 unter Hinweis auf den Fall „Arapi“, 37, den Fall „Hickey“, 38, und den Fall „Symeou“, 39; Arnold, StV 2015, 588, 593.

128 Im Überblick Frank Meyer, in: Ambos/König/Rackow (Anm. 110), § 79 Rdn. 811. Das betrifft v. a. die Frage der Verhältnismäßigkeit oder die Prüfung der Anordnungsvoraussetzungen und Versagungsgründe wie z.B. der Verjährung, siehe auch Schomburg, in: Breitenmoser/Gless/ Lagodny (Anm. 116), S. 221, 233.

129 Vgl. Schomburg, in: Breitenmoser/Gless/Lagodny (Anm. 116), S. 221, 235f.; Suominen (Anm. 61), S. 315; intuitiv müsste es als Zugeständnis an ein System des gespaltenen Rechtsschutzes eine Bindungswirkung an Entscheidungen ausländischer Instanzen geben. Ohne Einschränkungen lässt sich die Forderung nach gegenseitiger Anerkennung von Versagungsentscheidungen aber nicht generalisieren. Versagungsgründe können von Land zu Land und situativ variieren; auch kann eine entscheidungsrelevante nachträgliche Veränderung der Verhältnisse eintreten.

130 Dazu nun auch Art. 8 der Richtlinie 2016/343 des Europäischen Parlaments und des Rates vom 09. 03. 2016 zur Stärkung bestimmter Aspekte der Unschuldsvermutung und des Rechts auf Anwesenheit in der Verhandlung in Strafverfahren. 
Vordergrund steht. In diese Kategorie fällt die Prüfung, ob vor einem Abwesenheitsurteils ordnungsgemäß geladen wurde oder (wenn dies nicht der Fall war) dem Verurteilten im Falle der Überstellung wirklich ein wirksames Recht zur Verfügung steht, eine Überprüfung des Urteils in tatsächlicher und rechtlicher Hinsicht zu erwirken ${ }^{131}$.

\section{(2) Weitere Beispiele verschränkt-transnationaler Strafverfolgung}

Die Charakteristika verschränkt-transnationaler Strafverfolgung spielen im Vergleich zum RB EuHB in den rechtsdogmatischen und rechtspolitischen Bewertungen anderer Kooperationsbereiche nur eine untergeordnete Rolle. Es dominiert die nationalstaatliche Perspektive, die bewirkt, dass Eingriff und Eingriffsrechtfertigung exklusiv über das nationale Recht bemessen und etwaige (zumindest mittelbar) grundrechtsrelevante Interaktionen auf supranationaler Ebene invisibilisiert werden ${ }^{132}$. Dies ist umso bedenklicher, als die ebenen- und staatenübergreifende Zusammenarbeit immer intensiver, vielgestaltiger und komplexer wird. Die Koordinierung von Ermittlungen und Jurisdiktionsabsprachen im Rahmen von Eurojust ${ }^{133}$ gehört noch zu den überschaubaren Phänomenen. Anders sieht es schon für die operationelle Planung und Durchführung von multistaatlichen Ermittlungen durch Europol aus, die dann auch noch durch Datenverarbeitung und Datenanalyse durch Europol-Beamte unterstützt werden und sich vielleicht zusätzlich sogar gemeinsamer Ermittlungsgruppen als Verfolgungsinstrument bedienen, an denen dann wiederum Beamte aus einzelnen Mitgliedstaaten von Europol, Eurojust oder sogar aus Drittstaaten beteiligt sein können und deren Errichtungsvereinbarungen oftmals entscheidend von Europol oder Eurojust mitgestaltet werden ${ }^{134}$. Ähnlich unübersichtlich geht es beim Informationsaustausch zu. In einer wachsenden Anzahl von Datenbanken werden Daten gemeinsam gesammelt und ausgetauscht, Polizeibehörden gewähren einander grenzüberschreitend Zugriff auf die eigenen Datenbestände unter den gleichen Bedingungen wie nationalen Behörden; nichtstrafrechtliche Datenbanken werden dem

131 Vgl. BVerfG, Urteil v. 15. 12. 2015, 2 BvR 2735/14, wo auch die Verfassungskonformität der Schutzstandards in Art. 4a RB-EuHb festgestellt wurde. Das Beispiel, in Abwesenheit Verurteilte ausliefern zu müssen, wird bei Masing insofern nicht zutreffend eingeordnet, JZ 2015, 477, 487.

132 Vgl. hierzu auch Hüttemann (Anm. 118), S. 198 ff., 211 ff.; die Eingriffsqualität vermeintlich nur unterstützenden Verhaltens der EU-Agenturen wird für gewöhnlich verneint; vgl. EuG, Rs. T193/04 (Tillack/Kommission), Slg. 2006, II-3995, Rdn. $68 \mathrm{ff}$.

133 Dazu Böse, in: Böse/Frank Meyer/Schneider (Anm. 91), S. 336ff.; zum forum shopping Arnold, StV 2015, 588, 594.

134 Frank Meyer, Gedächtnisschrift für Weßlau, 2016, S. 193, 207 ff. 
Zugriff durch Strafverfolgungsbehörden geöffnet. Die daraus gewonnenen Informationen können wiederum mit anderen Daten verknüpft, weitergeleitet, gesammelt und ausgetauscht werden. Unter bestimmten Voraussetzungen werden diese Daten auch mit Drittstaaten geteilt, die außerhalb des GRC-Bindungsraums stehen. Diese zugegebenermaßen extrem verkürzte Darstellung vermag dennoch zu illustrieren, dass Zweckbindung und Verhältnismäßigkeit der Datenverarbeitung sowie die effektive Ausübung von Auskunfts-, Berichtigungs- und Löschungsrechten nur noch schwer zu gewährleisten sind ${ }^{135}$. Letztlich verfügt keine Instanz mehr über einen Gesamtüberblick hinsichtlich aller Datenverarbeitungsvorgänge, die eine bestimmte Person betreffen, sodass eine umfassende, effektive Rechtskontrolle gar nicht mehr möglich ist. Stattdessen konzentriert sich die Kontrolle auf die einzelnen Verarbeitungsschritte, soweit diese überhaupt bekannt sind ${ }^{136}$. Die Protokollierungspflichten aus der neuen Datenschutzrichtlinie 2016/680 markieren insoweit einen substanziellen Fortschritt, mit dem die Basis für einen verbesserten Rechtsschutz geschaffen wird.

Das Beispiel des Informationsaustauschs steht damit symptomatisch für ein allgemeines Versäumnis, struktur- und gefährdungsangepassten Grundrechtsschutz zu eröffnen. Aufgrund der Fokussierung nationaler verfahrensführender Stellen auf den letzten unmittelbaren Eingriff kommt es zu einer Partikularisierung des Grundrechtsschutzes unter Ausblendung der ebenenübergreifenden Verschränktheit und institutionellen Ursprünge vieler Handlungen und Ermittlungen. Ein integriert-transnationaler Gesamtermittlungskomplex wird in nationale Episoden aufgebrochen, nirgends aber in der Gesamtheit analysiert und grundrechtlich bewertet. Hier sind nationale Gerichte aufgerufen, nicht mehr den Blick vor Implikationen einer verschränkt-transnationalen Strafverfolgung zu verschließen, sondern anhand konkreter Fälle Probleme zuzuspitzen und dem EuGH im Interesse der europäischen Strafrechtspflege prononcierte Vorlagefragen zu stellen ${ }^{137}$.

135 Hierzu nun bemüht Richtlinie 2016/680 vom 27. 4. 2016 zum Schutz natürlicher Personen bei der Verarbeitung, Ermittlung, Aufdeckung oder Verfolgung von Straftaten oder der Strafvollstreckung sowie zum freien Datenverkehr und zur Aufhebung des Rahmenbeschlusses 2008/977/JI des Rates.

136 Kritik an Lückenhaftigkeit und Uneinheitlichkeit der Regelung der Datenverarbeitung in der PJZS auch bei Kainer, EuR-Beiheft 2013, 87, 108.

137 Ausf. zur Problematik der Verbundverfolgung Frank Meyer, Gedächtnisschrift für Weßlau, S. 193, $198 \mathrm{ff}$. 


\section{b) Konkretisierung und Durchsetzung der Grundrechtsbindung}

Mit diesen Beispielen werden die zwei großen Herausforderungen deutlich, vor denen der Grundrechtsschutz in der PJZS steht. Es sind nicht nur die potenziell gefährdeten Grundrechte zu bestimmen, sondern im Falle nachweisbaren Bedarfs auch neue Grundrechte zu schöpfen oder bestehenden Rechten zumindest eine transnationale Komponente hinzuzufügen.

\section{(1) Potenziell gefährdete Grundrechte}

Mit Blick auf die obigen Beispiele kommen bei der Auslieferung die Würde des Menschen (Art. 1 GRC), das Verbot von Folter und unmenschlicher Strafe oder Behandlung (Art. 4 GRC), das Recht auf Achtung des Privat- und Familienlebens (Art. 5 GRC) als potenziell gefährdete Charta-Rechte in Frage. Speziell garantiert ist für die Auslieferung derzeit nur das (freilich bereits sekundärrechtlich verbürgte) Non-refoulement in Art. 19 Abs. 2 GRC. Auch die drohende Verletzung von Fair-trial-Rechten aus Art. 47 und 48 GRC im Anordnungsstaat kann deren Schutzbereich schon im Überstellungsverfahren eröffnen.

In den sonstigen, knapp umrissenen Beispielskonstellationen kommen insbesondere Art. 7 und (spezifisch für die Datenverarbeitung) Art. 8 GRC in Betracht, die aufgrund der ihnen immanenten transnational-vertikalen und -horizontalen Geltung geeignet sind, den Herausforderungen von sich grenzüberschreitend kumulierenden Eingriffen oder Jurisdiktionskonflikten ${ }^{138}$ wirksam zu begegnen (dazu auch unten). Sie könnten auch zur Quelle eines von Freizügigkeitserwägungen emanzipierten Ne-bis-in-idem-Schutzes werden.

Ein grundsätzliches Problem liegt für beide Kategorien in der Modellierung schützender Formen und spezifischer Verfahrensrechte zur Gewährleistung eines fairen Verfahrens im Rahmen der verschiedenen Kooperationsverfahren. Jedoch lehnt die wohl immer noch vorherrschende Auffassung eine Anwendung von Art. 6 EMRK (Art. 47, 48 GRC) in der Rechtshilfe $\mathrm{ab}^{139}$. Es ist zu hinterfragen, ob diese Sichtweise in der EU immer noch zeitgemäß und strukturangemessen ist. Geht man davon aus, dass Art. 47 und Art. 48 GRC zumindest dann gelten müssen $^{140}$, wenn Handlungen des Vollstreckungsstaates Verfahrenshandlungen

138 Frank Meyer, in: Böse/Frank Meyer/Schneider (Anm. 91), S. 169, 194 ff.

139 Zur Diskussion Schaffner, Das Individuum im internationalen Rechtshilferecht in Strafsachen, 2013, S. 48f.; Donatsch/Heimgartner/Frank Meyer/Simonek, Internationale Rechtshilfe, 2. Aufl. $2015, \S 5$.

140 Wovon offenbar auch der EuGH bei der Prüfung einzelner Ablehnungsgründe interessanterweise ausgeht, EuGH, Rs. C-399/11 (Melloni), Rdn. 49 ff., 53. 
in einem Strafverfahren des Ausstellungsstaates substituieren oder der Vollstreckungsakt nichts anderes als eine (verdeckt-mittelbare) Form der Ausübung extraterritorialer Hoheitsgewalt durch den strafverfahrensführenden Staat ist, erweist sich eine funktional-äquivalente Rekonstruktion des Rechts auf ein faires Verfahren und insb. auf effektive Verteidigung in seiner transnational-horizontalen Dimension als geboten ${ }^{141}$. Gleiches gilt in Bezug auf die Verschränkung und Verkopplung multipler nationaler Verfahren über supranationale Einrichtungen. Auch für sie braucht es spezifische Schutzmechanismen (die freilich auch anderen Grundrechten wie insb. Art. 8 GRC geschuldet sind).

Im Schrifttum wird zwar zutreffend darauf hingewiesen, dass die Situation eines Rechtshilfeverfahrens sich signifikant von einem normalen Strafverfahren unterscheidet und daher auch unter der Prämisse effektiven Individualschutzes keine Gleichstellung geboten sei ${ }^{142}$. Daran ist gewiss richtig, dass es nicht um eine undifferenzierte Einspiegelung von Fair-trial-Rechten in das Rechtshilfeverfahren gehen kann, weil diese teils nicht passen, teils nicht genügen. In der Tat geht es vielmehr um die Respezifizierung des normativen Kerns eines fairen Verfahrens für die Rechtshilfe. Dabei kann sich ergeben, dass diese Schutzgehalte bereits durch andere Grundrechte abgesichert sind ${ }^{143}$. Insofern trägt die Diskussion zugegebenermaßen die Züge eines Stellvertreterkrieges, bei dem es im Kern um den Ankerpunkt für die funktional-äquivalente Rekonstruktion und Fortbildung von Strafverfahrensrechten in der Rechtshilfe geht, von dem aus ein hinreichendes Schutzniveau zu konzipieren und etablieren ist ${ }^{144}$.

Dabei wäre neben vielem anderen der Prozesskostenhilfe, den grenzüberschreitenden Vertretungsrechten oder dem effektiven Aktenzugang auch an eine an den bisherigen praktischen Erfahrungen ausgerichtete - Erweiterung und Präzisierung der Versagungs- und Überprüfungsmöglichkeiten zu denken. Auch die Subsidiarität gegenüber anderen, gleich effektiven verfahrensfördernden

141 Siehe auch Hüttemann (Anm. 118), S. 211 ff.; Frank Meyer, in: v. d. Groeben/Schwarze/Hatje (Anm. 69), Vor Art. 82ff. Rdn. 26. Erst recht sind die Prämissen der Vertragstheorie und die Qualifizierung als Verwaltungsverfahren in einem als single legal area begriffenen Strafverfolgungsraum nicht mehr aufrechtzuerhalten.

142 Schaffner (Anm. 139), S. 44f.; krit a. Vogel, in: Grützner/Pötz/Kress (Hrsg.), Internationaler Rechtshilfeverkehr in Strafsachen, 37. Lfg. 2014, Vor § 1 Rdn. 41.

143 Schaffner (Anm. 139) S. 52f., neigt der Auffassung zu, dass in Auslieferungssachen angemessener Schutz auch über andere Menschenrechte zu erreichen ist.

144 Über das sog. Kombinationsprinzip, Vogel, in: Grützner/Pötz/Kress (Anm. 142), Vor § 1 Rdn. 41, lässt sich das nicht erreichen, weil wechselseitige Kompensation einen gewissen Grad an Abgestimmtheit verlangt und es sich das Schutzniveau eines nationalen Strafverfahren zur Referenzmarke nimmt. Auf diesem Weg lassen sich Bedrohungssituationen nicht meistern. Unter Umständen lässt das Kombinationsprinzip sogar neue Bedrohungen entstehen. 
Maßnahmen wäre abzusichern ${ }^{145}$. In diesem Zusammenhang drängt die Schutzpflichtdimension der berührten Grundrechte die Mitgliedstaaten zu einer zügigen Umsetzung der den RB EuHB komplementierenden Rahmenbeschlüsse, sehen diese doch wirksame Alternativen zur Untersuchungshaft und zur Überstellung vor.

\section{(2) Räumliche Reichweite des Grundrechtsschutzes}

Präzisierungsbedürftig ist in diesem Zusammenhang auch, auf welchen Grundrechtsraum sich die Bemessung der Eingriffswirkung zu beziehen hat. Dies betrifft verstärkt die Informationsrechtshilfe sowie die verschränkt-ebenenübergreifende Verfolgungszusammenarbeit zwischen Staaten und Agenturen. Die Eröffnung einer transnational-vertikalen und einer transnational-horizontalen Grundrechtsdimension drängt dazu, die grundrechtsdogmatische Bewertung von Eingriff und Eingriffsrechtfertigungen, insb. der Verhältnismäßigkeit, dimensionsadäquat zu transformieren. Da es im Beitrag um die Bindung der Mitgliedstaaten geht, ist vorrangig zu erörtern, inwiefern untereinander abgestimmte Eingriffe in mehreren Staaten in eine aggregierende Verhältnismäßigkeitsprüfung (bei der Anordnung oder Überprüfung von Ermittlungsmaßnahmen) einfließen müssen und Handlungen supranationaler Einrichtungen (da umfassende Kontrollmechanismen bislang fehlen) dem ausführenden Nationalstaat zuzurechnen sind.

\section{(3) Praktische Umsetzung}

Die Grundrechtsbindungen in der Rechtshilfe sind primär durch GRC-konforme Anwendung der für die jeweilige Rechtshilfemaßnahme stipulierten Zulässigkeitsvoraussetzungen und Versagungsgründe zu realisieren. Um auf unvorhergesehene Fälle und Ausnahmekonstellationen reagieren zu können, ist ggf. auf dafür eingerichtete allgemeine Auffangklauseln auszuweichen ${ }^{146}$. Enthalten verpflichtende Sekundärrechtsakte wie der RB-EuHB kein derartiges Sicherheitsnetz, geraten die Mitgliedstaaten dagegen in einen Zwiespalt zwischen der Effektivitätslogik nach Lesart des EuGH in „Radu“1477 und der Verpflichtung aus der GRC

145 Schomburg, in: Breitenmoser/Gless/Lagodny (Anm. 116), S. 221, fordert den Nachweis eines gescheiterten vorherigen Ladungsversuchs, S. 235. Bei Flucht oder Vereitelungsversuchen dürfte dieser Zwischenschritt entbehrlich sein.

146 Vgl. Art. 11 Abs. 1 lit. f RL-EEA: Versagung bei Unvereinbarkeit der Vollstreckung mit europäischen Grundrechten.

147 Unter Betonung der Notwendigkeit, die Wirksamkeit von Sekundärrechtsakten sicherzustellen, versagt der EuGH es mitgliedstaatlichen Gerichten, sich sowohl auf Primärrecht als auch auf 
zur Wahrung der primärrechtlichen Grundrechte. Denn wie die oben skizzenhaft vorgestellten Beispiele offenbaren, sind ein hinreichendes Grundrechtsschutzniveau und Primärrechtskonformität allgemein nicht automatisch mit der Verabschiedung eines Rahmenbeschlusses oder nunmehr einer Richtlinie verbunden. Die Rigidität des EuGH-Ansatzes hat zur Folge, dass das Nadelöhr „Vorlageverfahren“, das aufgrund des Fehlens einer Grundrechtsbeschwerde ohnehin schon jedweden Bottom-up-Ansatz empfindlich einengt, zusätzlich gedrosselt wird. Der Grundrechtsschutz des Betroffenen wäre damit nachhaltig eingeschränkt, aber nicht vollständig abgeschnitten. Allerdings ändert die bisher gezeigte Strenge des EuGH nichts an der grundsätzlichen Bindung an die GRC. Es wäre, wie die Aranyosi-Entscheidung zeigt, im konkreten Fall eben doch zulässig, eine Überstellung unter Berufung auf die GRC abzulehnen und dies in einem Vorabentscheidungsverfahren vom EuGH auch bestätigt zu bekommen. Selbst wenn der EuGH sich im konkreten Einzelfall im Verhältnis zu vorlegenden nationalen Gerichten einer materiellen Prüfung verweigern sollte, könnte er weder die materielle Bindung an die EMRK-Standards aus Art. 52 Abs. 3 GRC unterlaufen noch etwas an der eigenständigen Verpflichtung der Mitgliedstaaten zur Einhaltung der EMRK ändern. Dies gilt vor allem für jene Ausschnitte der Strafrechtspflege, in denen sich feste Standards auf EMRK-Ebene herausgebildet haben.

Auch der Vorlagebeschluss in der Rechtssache „Aranyosi“ war von der Überzeugung getragen, dass der EuGH nicht hinter den EGMR zurückfallen darf. Die EMRK bleibt als Rechts- und Kontrollrahmen anwendbar und drängt den EuGH dazu, im Verbund mit den nationalen Gerichten zumindest eine equivalent protection i.S.d. Bosphorus-Rspr. $\mathrm{zu}$ erreichen ${ }^{148}$. Es wurde bereits an anderer Stelle ausgeführt, dass schon deshalb für bestimmte Fallgruppen eine materielle Prüfung im Vollstreckungsstaat erfolgen können und den mitgliedstaatlichen Fachgerichten dazu zur Not der Rückgriff auf den europäischen ordre public offenstehen muss ${ }^{149}$. $\mathrm{Zu}$ den in der EMRK abgesicherten Fehlerkategorien gehören außer dem (ausdrücklich auch in Art. 19 Abs. 2 GRC verbrieften) nonrefoulement, die stets zitierten systemischen Mängel in ausländischen Verfah-

nationales Verfassungsrecht mit höheren menschenrechtlichen Schutzstandards zu berufen; vgl. EuGH, Rs. C-681/11 (Schenker), Rdn. 33ff.; EuGH, Rs. C-399/11 (Melloni), Rdn. 59, 60; EuGH, Urteil v. 29. 01. 2013, Rs. C-396/11 (Radu), Rdn. 36; EuGH, Urteil v. 1. 12. 2008, Rs. C-388/08 (Leymann u. Pustovarov); EuGH, Urteil v. 07. 09. 2010, Rs. C-261/09 (Mantello), Slg. 2010, I-11477, Rdn. 37; EuGH, Urteil v. 28. 6. 2012, Rs. C-192/12 PPU (Melvin West), Rdn. 55.

148 Frank Meyer, in: Ambos/König/Rackow (Anm. 110), § 79 Rdn. 811.

149 Dazu Übersicht bei Frank Meyer, in: Ambos/König/Rackow (Anm. 110), § 79 Rdn. 811 sowie Rn. 816; siehe auch Gaede (Anm. 54), Bd. 9, § 3 Rdn. $49 \mathrm{ff}$. 
ren ${ }^{150}$, schwere rechtsstaatliche Mängel im Einzelfall, die das Fundament für ein faires Verfahren zerstören, grob unverhältnismäßige oder erniedrigende Strafe und eben unzumutbare Haftbedingungen ${ }^{151}$. Demnach wäre es auch aus unionsgerichtlicher Perspektive geboten, den nationalen Fachgerichten eine mindestens in diesem Umfang erweiterte Prüfung zu gestatten, auch wenn das Sekundärrecht i.V.m. nationalem Rechtshilferecht von einer grundsätzlichen Kooperationspflicht ausgeht.

\section{(4) Letzter Ausweg „EGMR“}

Verweigert sich der EuGH einer Prüfung oder Konkretisierung der GRC, stünde den Betroffenen zumindest dort, wo sich innerhalb der EMRK Mindeststandards herauskristallisiert haben, der Weg vor den EGMR offen. Der EGMR beansprucht auch bei Determinierung eines (legislativen, exekutiven oder judikativen) nationalen Umsetzungsaktes durch EU-Recht eine eingeschränkte Prüfungskompetenz ${ }^{152}$. Der Gerichtshof enthält sich zwar einer konkreten Nachprüfung des Beschwerdevorwurfs, solange die Unionsrechtsordnung im konkreten Vergleich mit den EMRK-Standards einen gleichwertigen Schutz bietet. Das Versagen der Schutzstrukturen innerhalb der EU würde indessen zur Aktivierung der Prüfungskompetenz des EGMR gegenüber den Mitgliedstaaten führen, wenn weder die nationalen Justizsysteme noch die Unionsgerichte das Unionsrecht in einer Weise anwenden, wie es ein praktisch wirksamer Schutz der in der konkreten Situation materiell berührten Konventionsrechte erfordern würde ${ }^{153}$.

Schwieriger wird es dagegen, wenn - was nicht selten der Fall ist - der EGMR-Rechtsprechung keine Blaupause für die Problembehandlung zu entnehmen ist, weil es auf Europaratsebene keine analogen Fälle gibt oder weil der EGMR die EMRK-Rechte noch nicht als transnational-horizontale Gewährleistungen imaginiert hat bzw. das konkret betroffene Recht per se nicht oder nicht in gleichem Umfang durch die EMRK geschützt ist; dies betrifft z.B. das transnationale Doppelbestrafungsverbot aus Art. 50 GRC. Der EGMR könnte Grundrechtsbeeinträchtigungen dieser Art kaum abhelfen. Bereits faktisch sollte man das

150 Dieser Ablehnungsgrund ist der Rechtsprechung zum Asylrecht entlehnt: EuGH Urteil v. 21. 12. 2011, Rs. C-411/10 u. 493/10 (N.S.u.a.); EGMR, Urteil v. 21. 01. 2011 - 30696/09 (M.S.S).

$151 \mathrm{Zu}$ denken ist ferner an missbräuchliche Nutzung des EuHb zur Erzwingung von Aussagen anstelle des Bemühens um eine rogatorische Vernehmung im Wege der Rechtshilfe; Frank Meyer, in: Ambos/König/Rackow (Anm. 110), § 79 Rdn. 816.

152 EGMR (GK), Urteil v. 30. 06. 2005 - 45036/98 (Bosphorus v. Irland), Rdn. 156, 166.

153 EGMR, Urteil v. 06. 12. 2012 - 12323/11 (Michaud v. Frankreich), NJW 2013, 3423; Frank Meyer (Anm. 7), Bd. 3, § 38 Rdn. 20, 25. 
grundrechtsdogmatische Potenzial des Gerichtshofs, die EMRK-Rechte in die Unionsrechtsordnung hineinzukonkretisieren und kohärente integrierte Standards für die Ausübung supranationaler Hoheitsgewalt zu entwickeln, realistischerweise nicht überschätzen. Der EGMR bleibt bislang in international-horizontalem Denken verhaftet. Die Geltungsdimensionen der GRC reichen zudem über diejenigen der EMRK hinaus ${ }^{154}$ : Dies betrifft neben dem schon genannten transnationalen Ne-bis-in-idem-Grundsatz, die Behandlung von Jurisdiktionskonflikten, die Entfaltung des Rechts auf effektive Verteidigung in transnational-horizontaler und transnational-vertikaler Dimension, die grundrechtsdogmatische Durchdeklinierung der unionsweiten Zusammenarbeit von Staaten und supranationalen Agenturen auf überstaatlicher Ebene ebenso wie die Behandlung mittelbarer und kumulativer Eingriffe in supranationalen Verfolgungsräumen. Das Beschreiten des Rechtswegs vor den EGMR hätte in derartigen Fällen keine Aussicht auf Erfolg. Lediglich die einzelnen Implementierungsakte der Mitgliedstaaten könnten isoliert zur Prüfung gestellt werden.

\section{c) Residualverantwortung}

Vor diesem Hintergrund ist hervorzuheben, dass die Herleitung und Einführung von Schutzstandards für die unterschiedlichen Formen der Zusammenarbeit in der EU eine Aufgabe der Unionsorgane ist und nach den primärrechtlichen Verfassungsstrukturen eigentlich die EU-Legislative gefordert wäre, durch Nachbearbeitung defizitärer Instrumente Lücken zu schließen oder Spielräume für die Rechtsanwender zu schaffen, die ein inkrementell-organisches Heranwachsen gefährdungsadäquater Schutzstandards in der Praxis zulassen ${ }^{155}$. Dies geböten bereits die positiven Schutzpflichten, welche die Unionsorgane bezüglich zahlreicher GRC-Rechte treffen ${ }^{156}$. Doch auch diese Dimension des Grundrechtsschutzes ist auf Unionsebene noch nicht vollständig exploriert worden.

154 Es erscheint doch fraglich, ob allein der Beitritt eines neuen Mitglieds zur EMRK eine derartige quantensprungartige Wirkungsexpansion des Grundrechtskatalogs, zu dem der Beitritt erfolgt, herbeiführen kann.

155 Unionsweit verbindliche Regelungen für Zusicherungen inkl. der Zuständigkeitsfrage dürften z. B. jenseits der Gestaltungsbefugnis der Justiz liegen; im Interesse hinreichender Vergleichbarkeit, Vorhersehbarkeit und Verlässlichkeit bedarf es einheitlicher legislativer Standards.

156 Zur Schutzpflicht aus Art. 7 GRC zur Regulierung der Beilegung von Jurisdiktionskonflikten, Frank Meyer in: M. Böse/Frank Meyer/A. Schneider (Anm. 91), S. 199, $211 \mathrm{ff}$. 


\section{Bindung der mitgliedstaatlichen Verfahrensdurchführung an die GRC}

Besonders herausfordernd ist die Konkretisierung der GRC-Bindung innerhalb der mitgliedstaatlichen Durchführung von Strafverfahren. Dies hat seinen Grund zum einen in der Vielzahl möglicher Anwendungsfelder und zum anderen in deren mitunter hoher Komplexität. Betroffen sind so unterschiedliche Bereiche wie Verteidigungs- und Opferrechte, Verwertungsverbote, Verfahrenshindernisse, die Gestaltung der staatsanwaltschaftlichen Ermittlungen und des gerichtlichen Hauptverfahrens, verfahrensbeendende Entscheidungen oder das Verjährungsrecht. So hat der EuGH in der Rechtssache Steffensen ${ }^{157}$ deutlich gemacht, dass auch nationale Beweisregeln in den Geltungsbereich des Unionsrechts fallen können, und mitgliedstaatlichen Gerichten dabei die Prüfung auferlegt, ob bestimmte (in einem Verwaltungsverfahren gesammelte) Beweismittel auszuschließen sind, weil ein kontradiktorisches Gegenrecht ${ }^{158}$ nicht wirksam ausgeübt werden konnte und im Falle der Beweisverwertung damit die wirksame Ausübung eines gemeinschaftlich gewährten Rechts vereitelt zu werden drohte. Als Quelle für das zu erwägende Beweisverwertungsverbot brachte der EuGH alternativ zum Effektivitätsgrundsatz auch den Grundsatz des fairen Verfahrens ins Spiel. In der Rechtssache Taricco geht der EUGH sogar so weit, nationale Verjährungsvorschriften für unanwendbar zu erklären, wenn sie - aufgrund ihrer kurzen Laufzeiten - keine wirksame Verfolgung schwerer Verletzungen unionaler Interessen ermöglichen ${ }^{159}$. Als äußerst heikel wird jedoch vor allem eingestuft, dass die Anwendung mitgliedstaatlichen Verfahrensrechts im indirekten Vollzug unter „Durchführung des Unionsrechts“ fallen könnte und damit auch der GRC unterläge $^{160}$. Dies scheint vor allem der Praxis Sorgen zu bereiten. Die Bindung an die GRC ist jedoch keine Sache der rechtspolitischen Bereitschaft oder verfahrenstechnischen Opportunität, sondern das Resultat konsequenter Anwendung der primärrechtlichen Rechtsquellen. Dieser rechtspraktisch enorm wichtigen Frage ist daher zunächst vorrangig und grundsätzlich nachzugehen, bevor im Anschluss einige konkrete Anwendungssituationen an die Reihe kommen.

157 EuGH, Urteil v. 10. 04. 2003, Rs. C-276/01 (Steffensen), Slg. 2003, I-3735, Rdn. 76, 80.

158 Es ging um ein gemeinschaftsrechtliches Recht auf ein Gegengutachten nach einer Richtlinie über amtliche Lebensmittelüberwachung.

159 EuGH v. 8. 9. 2015, Rs. C-105/14 (Taricco), Rdn. 47,49; siehe unten Anm. 182; vgl. dazu Billis, NJECL 7 (2016), S. 20, 21 ff.; Giuffrida, NJECL 7 (2016), S. 100, 101 ff; Gaede, wistra 2016, 89, $92 \mathrm{ff}$. 160 Dagegen Kingreen, in: Calliess/Ruffert (Anm. 9), Art. 51 Rdn. 12; Scheuing, EuR 2005, 162, 168; Ladenburger, in: Tettinger/Stern (Hrsg.), Kölner Gemeinschaftskommentar zur Europäischen Grundrechte-Charta, 2006, Art. 51 Rdn. 45. 


\section{a) Anwendung nationalen Verfahrensrechts als Durchführung von Unionsrecht}

Die Problematik ist nicht neu und wurde im öffentlichen Recht bereits intensiv diskutiert. Als Hauptargument für eine Bindung lässt sich darauf verweisen, dass die Mitgliedstaaten und deren Organe GRC-verpflichtet sind, wenn sie Unionsrecht durchführen ${ }^{161}$, und dass auch mitgliedstaatliches Verfahrensrecht dort zu einem Vehikel der Durchführung wird, wo nationale Behörden und Gerichte zur Implementierung von Unionsrecht an- oder aufgerufen sind ${ }^{162}$. Dies gilt mithin auch, wenn Verletzungen von EU-induzierten Strafrechtsnormen ermittelt und verfolgt werden; dann stehen Strafverfahrens- und Sanktionsrecht im Dienste des Unionsrechts ${ }^{163}$. Primärrechtlich findet diese Sichtweise eine wichtige Stütze in Art. 291 Abs. 1 AEUV $^{164}$, wonach die Mitgliedstaaten ihren unionsrechtlichen Verpflichtungen gerade durch Maßnahmen im innerstaatlichen Recht nachzukommen haben und daher auch die Anwendung innerstaatlichen Rechts (zur Realisierung eines verbindlichen Unionsrechtsakts) funktional der „Durchführung“ von Unionsrecht dient. Diese Verkoppelung entspricht auch der Verfahrensabhängigkeit des materiellen Rechts ${ }^{165}$. Das Verfahrensrecht ist Mittel der Durchsetzung des materiellen Fachrechts (im Wege des indirekten Unionsvollzugs). Die Union greift hier auf die Rechtssysteme der Mitgliedstaaten zu (vgl. nochmals Art. 291 AEUV!), um das von ihr gesetzte Fachrecht implementieren oder durchsetzen zu lassen. In diesem Umfang liegt in der Anwendung des nationalen Verfahrensrechts zugleich die Ausübung supranationaler Hoheitsgewalt, für die mit der GRC gerade eine Bindung an eine umfassende, integrierte Grundrechtsordnung etabliert werden sollte. Andernfalls bliebe als möglicher Anwendungsfall der Justizgrundrechte nur der im Strafrecht noch gar nicht existente, unmittelbare Eigenvollzug durch Unionsorgane. Als verfassungsdogmatisches und teleologisches Argument spricht auch dieser Gesichtspunkt für eine GRC-Bindung bei der Anwendung nationalen Verfahrensrechts.

161 Jarass (Anm. 12), Art. 47 Rdn. 4; Art. 48 Rdn. 15, Art. 51 Rdn. 17.

162 Es wird dadurch „zum Teil der Gemeinschaftssphäre“, Schaller, EuZW 2003, 666, 672; GA La Pergola, Schlussanträge v. 28. 01.1997 in der Rs. C-323/95 (Hayes/Kronenberger), Slg. 1997, I1711, Rn. 8;

163 Unter „Durchführung“ fallen auch allgemeine remedial rules, wenn diese zur Durchsetzung einer unionsrechtlichen Verpflichtung ergriffen werden, EuGH, Urteil v. 22. 10. 2010, Rs. C-279/09 (DEB), Rdn. 111.

Jarass, NStZ 2012, 611, 613; ebenso Lange, NVwZ 2014, 169: Indienststellung der allgemeinen Prozessrechtsnormen.

164 Abs. 1 lautet: „Die Mitgliedstaaten ergreifen alle zur Durchführung der verbindlichen Rechtsakte der Union erforderlichen Maßnahmen nach innerstaatlichem Recht.“

165 Siehe oben Anm. 162. 
Dem wird entgegengehalten, dass sich die Anwendung allgemeiner nationaler Prozessregeln und des Beweisrechts im Besonderen nicht mit der Durchführung von Sekundärrecht in Verbindung bringen lasse ${ }^{166}$. Allenfalls kleine Teilausschnitte wiesen einen hinreichend engen Bezug zur Durchsetzung von verbindlichem Unionsrecht bzw. unionsrechtlich begründeten Ansprüchen auf. Eine zu stark ausgreifende GRC-Bindung beeinträchtige nicht nur die Verfahrensautonomie der Mitgliedstaaten ${ }^{167}$, sondern verstärke auch expansive unitarisierende Tendenzen im Anwendungsbereich der Grundrechte ${ }^{168}$. Es bestehe die potenzielle Gefahr einer Verdrängung von im Zweifel klarer ausdifferenzierten und dogmatisch anwendungssichereren nationalen Grundrechten ${ }^{169}$.

Daran ist zunächst richtig, dass das Verfahrensrecht nur insoweit erfasst sein soll und kann, als es konkret tatsächlich um die Anwendung von Unionsrecht geht $^{170}$. Das muss für das Ermittlungsverfahren ebenso gelten wie für das gerichtliche Hauptverfahren. Mit der GRC sollte für die Ausübung supranationaler Hoheitsgewalt in der EU eine Bindung an eine umfassende, integrierte Grundrechtsordnung etabliert werden; aus diesem Grund ist es auch zutreffend, Art. 51 GRC als Vehikel zur Konstitutionalisierung (der jeweils betroffenen Ebene und der diversen Schnittstellen bzw. des Gesamtsystems) im EU-Mehrebenensystem zu verstehen. Die GRC ist damit aber in Bezug auf die mitgliedstaatlichen Rechtssysteme anders als die EMRK nicht flächendeckend konzipiert. Sie erfasst nur diejenigen Segmente, in denen unionale Hoheitsgewalt ausgeübt wird. Für die Abgrenzung der Grundrechtskataloge ist mithin die Schlüsselfrage, ob mitgliedstaatliches Handeln in concreto als supranationale Hoheitsgewalt $\mathrm{zu}$ verstehen ist. Diese Differenzierung entspricht auch der supranationalen Optik von Art. 51 GRC.

Gelangt die GRC nach dieser Leitlinie zur Anwendung, baut sich dadurch aber in der Tat ein Spannungsverhältnis zwischen Unitarisierung und Partikularisierung des Grundrechtsschutzes auf. Jedoch wird sich die Unitarisierungswirkung (zumindest für den Moment) noch in Grenzen halten, solange die Grund-

166 Frenz (Anm. 34), Rdn. 256.

167 Ausgestaltung des Verfahrens, Organisation der Justizinstitutionen und Rechtsschutz obliegen im mittelbaren Vollzug den Mitgliedstaaten. Diese Autonomie ist indessen begrenzt durch Erfordernisse der Äquivalenz und Effizienz hergeleitet aus dem Prinzip der Unionstreue; dazu Kahl, in: Calliess/Ruffert (Hrsg.), EUV, Art. 4 Rdn. 62; EuGH Rs. $45 / 76$ (Comet), Slg. 1976, 2043, Rdn. 11, 18.

168 Masing, JZ 2015, 477, 484, 486; Ohler, NVwZ 2013, 1433, 1438; Thym, NVwZ 2013, 889.

169 Vgl. Masing, JZ 2015, 477, 486.

170 EuGH, Urteil v. 22. 10. 2010, Rs. C 279/09 (DEB), Rdn. 111; Jarass (Anm. 12), Art. 51 Rdn. 17. Diesen Bezug können aber auch die Erfordernisse der Äquivalenz und Effizienz (hergeleitet aus dem Prinzip der Unionstreue) herstellen. 
rechtsgefäße der GRC (im Wesentlichen) noch mit den Mindeststandardgehalten der EMRK gefüllt sind. Eine weitergehende Unitarisierung erscheint jedoch dann indiziert, wenn Spezifika der Unionsrechtsdurchführung eine Anpassung bzw. Erhöhung des Schutzniveaus verlangen. Diese Notwendigkeit kann beispielsweise eintreten, wenn sich aus dem anwendungsbestimmenden Unionsrecht bestimmte Vorgaben mit unionaler Grundrechtsrelevanz ergeben (dazu sogleich unten d) u. f) $)^{171}$, was der wirkungsbezogenen Logik des Unionsrechts entspricht, oder wenn Grundrechtsgefährdungen gewisse unionale Nuancierungen erfahren, die in der EGMR-Rspr. nicht abgebildet sind, namentlich die schon oben genannten Problemkreise des transnationalen ne bis in idem und der verschränkt-komplementären transnationalen Verbundverfolgung.

Demnach bleiben Konkurrenz- und Kollisionslagen mit dem nationalen Verfassungsrecht selbst bei der Anwendung nationalen Verfahrensrechts möglich. Hier kann es im Falle eines unabweisbaren Unitarisierungsbedarfs dazu kommen, dass nationale Grundrechte (und ggf. nationale Verfahrensregeln) verdrängt werden. Die grundrechtliche Fortbildungskompetenz ist aber auch im supranationalen Hoheitsbereich nicht grenzenlos. Art. 51 Abs. 2 GRC macht deutlich, dass eine Aktivierung der GRC für massive Unitarisierungen und gar Umformungen des nationalen Prozessrechts jenseits von Art. 82 Abs. 1 und 2 AEUV primärrechtlich unzulässig ist. Ebenfalls $\mathrm{zu}$ wahren sind Subsidiaritätsprinzip ${ }^{172}$ und Identitätsschut $^{173}$. Die genauen Grenzen (insb. die Schwellen des Identitätsvorbehalts) lassen sich indessen nur in der konkreten Anwendungssituation festlegen.

Entscheidend muss danach sein, wie weit und tief der unionsrechtliche Bezug in der konkreten Anwendungssituation reicht. Das hängt zum ersten von der Anwendungsfallgruppe ab und zum zweiten von der spezifischen Reichweite unionsrechtlicher Verpflichtungen innerhalb der jeweils auftretenden konkreten rechtlichen Problemstellungen. Unterschieden wird nachfolgend zwischen dem Erlass nationaler Verwaltungs- und Verfahrensvorschriften zur Durchführung von Unionsrecht, der punktuellen Gewährleistung einzelner unionsrechtlich vorgegebener Verfahrensrechte, der Neutralisierung nationaler Sanktionsvorschriften durch Sekundärrecht oder Grundfreiheiten, verfahrensbeendenden Entscheidungen und Strafzumessung.

171 Z.B. aufgrund des Effektivitätsgrundsatzes, Kahl, in: Calliess/Ruffert (Anm. 9), Art. 4 Rdn. 62; EuGH Rs. 45/76 (Comet), Slg. 1976, 2043, Rdn. 11, 18; allerdings wäre es denkbar, dass die ausgelöste Grundrechtsgeltung im Ergebnis zu einer Störung der Durchsetzung führen könnte.

172 Kingreen, in: Calliess/Ruffert (Anm. 9), Art. 51 Rdn. 6-GRC nur dort relevant, wo im Rahmen der leistungsrechtlichen Funktion zum Schutze der Grundrechte gehandelt wird.

173 Ohler, NVwZ 2013, 1433, 1437, vgl. auch Thym, JZ 2015, 53, 58. 


\section{b) Erlass nationaler Verwaltungs- und Verfahrensvorschriften zur Umsetzung von Unionsrecht}

Hierzu zählen (neben den schon oben behandelten harmonisierten Vorschriften des Rechtshilfeverfahrens) Regelungen zu den Roadmap-Richtlinien, welche sich um eine Annäherung von Mindestverteidigungsrechten bemühen und im nationalen Prozessrecht umzusetzen sind ${ }^{174}$. Ebenso $\mathrm{zu}$ erwähnen sind sonstige verfahrensrechtliche Bestimmungen, mit denen die Leistungsfähigkeit des Grundsatzes der gegenseitigen Anerkennung gefördert werden soll (Art. 82 Abs. 2 AEUV). Verfahrensrechtliche Verbürgungen erfahren durch die GRC eine primärrechtliche Unterfütterung, wenn sie sich in einem Charta-Recht lozieren lassen, was zumindest für die Roadmap zutreffen dürfte. In diesem Umfang müsste zudem wirksamer Rechtsschutz gem. Art. 47 GRC gewährleistet sein, um Verletzungen gerichtlich rügen zu können. In Verbindung mit dem Effektivitätsprinzip könnte sich eine drohende Vereitelung des Rechts auch in der Unverwertbarkeit von Beweismitteln äußern, die unter Verletzung des Rechts gesammelt wurden. Dies dürfte aber ganz entscheidend auch von der Schutzrichtung des jeweiligen Rechts abhängen.

In unmittelbarem Zusammenhang mit dieser Anwendungsfallgruppe stehen verfahrensrechtliche Gewährleistungen, die das Unionsrecht eingeführt hat, welche sich aber nicht in konkreten nationalen Verfahrensregelungen niedergeschlagen haben.

\section{c) Punktuelle Rechtsgewährleistungen}

Regelt das Unionsrecht einzelne Rechtsgewährleistungen, bringt dies auch die GRC zur Anwendung. Die Unionsrechtsrelevanz dieser Vorgabe beschränkt sich aber auf die Auslegung und die unionsrechtskonforme Anwendung des Rechts. Sachlich einschlägige Grundrechte können dabei verstärkend oder als Gegenpole wirken. Die GRC dürfte auch hier einen effektiven Rechtsschutzmechanismus zur Rüge etwaiger Rechtsverletzungen verlangen. In Verbindung mit dem Effektivitätsprinzip ist wiederum an eine mögliche Unverwertbarkeit von Beweismitteln zu denken, wenn andernfalls die wirksame Ausübung des betroffenen Rechts vereitelt würde.

174 Überblick bei Brodowski, ZIS 2015, 79, 89ff.; Frank Meyer, in: v. d. Groeben/Schwarze/Hatje (Anm. 69), Art. 82 Rdn. 44 ff.; Vogel/Eisele, in: Grabitz/Hilf/Nettesheim (Hrsg.), AEUV, 57. Lfg. 2015, Art. 82 Rdn. $104 \mathrm{ff}$. 


\section{d) Ermittlung und Verfolgung von Verletzungen EU-induzierter Strafrechtsnormen}

Führen die Mitgliedstaaten materielles Unionsrecht durch, so ist dies als Ausübung supranationaler Hoheitsgewalt zu verstehen und führt zur Anwendbarkeit aller Prozessgrundrechte im nationalen Durchführungsverfahren. Danach wären die Art. $47 \mathrm{ff}$. GRC immer dann zu beachten, wenn nationale Strafverfolgungsbehörden Ermittlungs- und Verfolgungsmaßnahmen wegen Verstößen gegen EUrechtlich induzierte ${ }^{175}$ Strafnormen anstellen ${ }^{176}$. Zudem müssten bei Entscheidungen über Ermittlungsmaßnahmen und Prozesshandlungen grundsätzlich auch betroffene materielle Charta-Rechte in das Kalkül der Entscheider einfließen. Demgegenüber gelangt die GRC für nationale Durchsetzungsvorschriften wie gesehen nicht zur Anwendung, wenn das zugrundeliegende (durchzusetzende) Fachrecht zwar bestimmte materielle Aspekte unionsrechtlicher Provenienz regelt, jedoch weder unmittelbar noch mittelbar Sanktionierungspflichten bestehen ${ }^{177}$. Vorstellbar, und praktisch wohl nicht ungewöhnlich, sind aber auch Gemengelagen von rein nationalen und EU-induzierten Normen. In solchen Mischfällen könnte sich auf den ersten Blick die Komplexität der Grundrechtsanwendung in Strafverfahren spürbar erhöhen, wenn in einem Verfahren je nach Delikt und Beschuldigtem unterschiedliche Grundrechtskataloge heranzuziehen sind und dadurch unterschiedliche grundrechtliche Schutzhöhen im selben Verfahren denkbar werden ${ }^{178}$. Praktische Schwierigkeiten der Verfahrensführung und Ungleichbehandlungen von einzelnen Beteiligten können die Folge sein.

175 Sei es aufgrund unmittelbarer Kriminalisierungspflichten oder allgemeiner Sanktionierungspflichten, sei es infolge der Loyalitätspflicht und des Effektivitätsprinzips; erfasst werden damit auch Konstellationen, bei denen nationale Straftatbestände gesetzgeberisch unberührt bleiben, aber funktional für Ziele, die vom Unionsrecht vorgegeben werden, in den Dienst gestellt worden sind, z. B. bei Umsetzung im Wege der europarechtskonformen Auslegung einer hinreichend breiten nationalen Vorschrift.

176 Vgl. auch Jarass, NStZ 2012, 611, 613; Zerbes/El-Ghazi, HRRS 2014, 209, 217; für den ne bis in idem-Schutz aus Art. 50 GRC ist das evident; vgl. z. B. EuGH, Urteil v. 05. 06. 2012, Rs. C-489/10 (Bonda).

177 Vgl. EuGH, Rs. C-144/95, Slg. 1996, I-2909, Rdn. 11f.; siehe oben Anm. 56.

178 Die Anwendbarkeit der Charta für ein Delikt greift nicht automatisch auf andere Delikte im Rahmen derselben prozessualen Tat über; anders nach einer sog. Dominotheorie aber Eckstein, ZIS 2013, 220, 224; Risse, HRRS 2014, 93, 102. Die dort angeführte EuGH-Fundstelle aus Åkerberg Fransson gibt für eine solche Theorie aber nichts her. Auch der grundrechtsdogmatische Kontext der Entscheidung wird nicht hinreichend bedacht. Während es für die Anwendung des freizügigkeitsgetragenen transnationalen Doppelbestrafungsverbots keine Rolle spielt, ob die in Rede stehenden Delikte einen unionsrechtlichen Ursprung haben oder nicht, ist dies für die Justizgrundrechte aus Art, 47-49 GRC unter dem Blickwinkel des Vorliegens supranationaler Hoheitsgewalt die zentrale Fragestellung. 
Die Auswirkungen dieser Bindung sind in der Sache vorläufig weniger gravierend, als es den Anschein haben mag. Denn die Inhalte der verbindlichen Charta-Grundrechte bestimmen sich aktuell noch primär nach der EMRK. Art. 52 Abs. 3 GRC bewirkt eine materielle Inkorporation der EMRK einschließlich der Rechtsprechung des EGMR ${ }^{179}$. Für Mitgliedstaaten ändert sich damit auf den ersten Blick zunächst nichts, da sie ohnehin EMRK-verpflichtet sind und ihr Handeln im nicht vollständig determinierten Bereich vor dem EGMR vollumfänglich überprüfbar ist. Die zusätzliche Bindung an die GRC über Art. 51 GRC hat daher gegenwärtig eine vergleichsweise geringe praktische Bedeutung. Es ist jedoch nicht nur theoretisch denkbar, sondern auch konzeptionell intendiert, dass die grundrechtlichen Anforderungen über die EMRK hinausreichen, vgl. Art. 52 Abs. 3 Satz 2 GRC. Die GRC weist multiple Grundrechtsdimensionen auf, die zum einen über bloße Mindeststandards hinausgehen sollen und zum anderen von vornherein kein Gegenstück in der EMRK haben. Wann und wie ChartaRechte i.S.v. Art. 52 Abs. 3 Satz 2 GRC über EMRK und ggf. nationales Verfassungsrecht hinausgehen müssen, gehört freilich zu den schwierigsten Fragen, die sich gegenwärtig in Bezug auf die GRC-Bindung im Strafverfahrensrecht stellen. Die vorliegende Abhandlung kann dazu nur einige Fingerzeige geben. Es sollten zwei Anwendungskontexte unterschieden werden: Zum einen kann sich aus unionsrechtlichen Verpflichtungen oder der Eigenschaft eines mitgliedstaatlichen Handelns als supranationale Hoheitsgewalt eine besondere unionale Grundrechtsdimension ergeben, die nicht - wie in normalen nationalen Verfahren durch nationale Grundrechte und EMRK aufgefangen wird. Zu dieser Kategorie gehören u.a. die oben genannten Fälle unionsrechtlich veranlasster Verfahrensvorschriften und Rechtsgewährleistungen i.V.m. dem Effektivitätsprinzip, aber auch der (zur Förderung der Freizügigkeit) transnationale Ne-bis-in-idem-Grundsatz. Gestützt auf den Effektivitätsgrundsatz könnte sich zum anderen erweisen, dass eine Annäherung nationaler Beweiserhebungs- und -verwertungspraktiken notwendig wird, wenn andernfalls die wirksame Durchsetzung des Unionsrechts auf dem Spiel steht ${ }^{180}$. Die GRC ist auch betroffen, wenn unter Berufung auf das Effektivitätsprinzip die Nichtanwendung nationaler Verfahrensregeln oder Ver-

179 Borowsky, in: Jürgen Meyer (Anm. 1), Art. 52 Rdn. 36; Ehlers, in: Ehlers (Anm. 12), S. 527.

180 Z.B. durch eine europäische Beweisverwertungslehre, wenn der Gedanke der gemeinschaftlichen, wirksamen Durchsetzung supranationalen Rechts eine Annäherung der nationalen Standards verlangt, um keine Wirksamkeitsdivergenzen zu produzieren. Die Position der Grundrechte ist in diesem Zusammenhang aber ambivalent. GRC-Rechte können Ausgangspunkt einer Verwertungsbeschränkung sein oder einer zu großzügigen Handhabung von Verwertungsfragen entgegenwirken; zu Fragen der Beweisverwertung äußert sich auch Marguery, Modern Journal 20 (2013), S. 282, 290. 
jährungsvorschriften damit begründet wird, dass bei Einhaltung der gesetzlichen Vorgaben eine wirksame Verfolgung von EU-einnahmerelevanten schweren Betrugsstraftaten nicht möglich ist ${ }^{181}$. Eine derartige Außerkraftsetzung nationalen Rechts darf europarechtlich nicht zu einer unzulässigen Einschränkung von Charta-Rechten führen ${ }^{182}$.

Soweit es im Rahmen unionsrechtlicher Verpflichtungen zur Zusammenarbeit mit anderen Staaten kommt, wäre überdies zu prüfen, ob nicht einzelne Verfahrensrechte wie z.B. der Beschleunigungsgrundsatz oder das Konfrontationsrecht eine besondere transnationale Deutung erfahren müssen, die dem Charakter der Zusammenarbeit als arbeitsteilig ausgeübte, supranationale Hoheitsgewalt Rechnung trägt und über die vorsichtigen Versuche des EGMR, die

181 EuGH v. 8. 9. 2015, Rs. C-105/14 (Taricco), Rdn. 47.

182 EuGH v. 8. 9. 2015, Rs. C-105/14 (Taricco), Rdn. 53 ff. Der EuGH konzentriert seine Prüfung auf Art. 49 GRC und beruft sich darauf, dass verjährungsrechtliche Regelungen weder Tatbestand noch Sanktion betreffen und damit nicht vom Rückwirkungsverbot erfasst sind. Dem ist die Einschätzung implizit, dass es sich bei Verjährungsvorschriften, um Normen handelt, die dem Prozessrecht zuzuordnen sind, und daher Art. 49 GRC nicht gilt; vgl. GA Kokott, Stellungnahme v. 06. 08. 2008 in der Rs. C-296/08 (Santesteban Goicoechea), Rdn. 45; Jarass Rn. 13; diff. Eser, in: Jürgen Meyer (Anm. 6), Art. 49 Rdn. 33 - Zugehörigkeit zum Prozessrecht kann variieren; entscheidend sei, dass kein schutzwürdiger Vertrauensschutztatbestand existiert. Eine Zuordnung zum Prozessrecht ist nicht in jedem Mitgliedstaat der EU gegeben; Begründung und Verständnis der Verjährungsvorschriften variieren in Europa stark, vgl. Zurbrügg, in: Niggli/Wiprächtiger, Basler Kommentar Strafrecht I, 3. Aufl. 2013, Vor Art. 97-101, Rdn. 11 ff. Insbesondere wenn die Verjährungsregeln materiell begründet werden, kann auch eine Beeinträchtigung des Schutzbereichs anderer Grundrechte eintreten. Gehörte das Verjährungsrecht zum materiellen Strafrecht, führte dies aber auch dazu, dass der Strafanspruch des Staates mit Ablauf der Verjährungsfrist materiell erlischt. Seine nachträgliche Reaktivierung würde mithin evident das Rückwirkungsverbot verletzen. Vor allem übersieht der EuGH aber, dass auch seine Behandlung der justiziellen Rechte unterkomplex ist, weil der Schutzbereich eines weiteren Grundrechts sachlich eröffnet ist und möglicherweise sogar eine Verletzung vorliegt. Der Gerichtshof ist offenbar nicht im Detail mit der neueren Rechtsprechung des EGMR vertraut. Dieser hat kürzlich, zugegebenermaßen durchaus überraschend, festgestellt, dass der Fairnessgrundsatz (also Art. 47 GRC) die Festlegung von Verjährungsfristen verlangt, um den mit Zeitablauf zunehmenden Schwierigkeiten für den Beklagten begegnen zu können sowie Rechtskraft und Rechtssicherheit zu gewährleisten, EGMR, 09. 01. 2013-21722/11 (Volkov v. Ukraine), Rdn. 137. Ein gänzliches Fehlen verletze die EMRK, der aber im Übrigen keine genauen Grenzen entnommen werden könnten. Mit diesen Ausführungen begründet der EGMR letztlich ein beschwerdefähiges subjektives Recht auf Einführung von hinreichend klaren Verjährungsvorschriften. Mit diesem Schutzgedanken ist eine Rechtsprechung unvereinbar, welche den nationalen Strafverfolgungsakteuren gestattet, das nationale Verjährungsrecht ohne weitere gesetzliche Präzisierung im Interesse effektiver Rechtsdurchsetzung außer Kraft setzen zu können. Die Sichtweise des EuGH ist somit wohl nicht mit der Rechtsprechung des EGMR vereinbar, die über Art. 52 Abs. 3 GRC bindend ist und auch nicht dem Effektivitätsgrundsatz weicht, sondern ihm Grenzen setzt. 
Einbeziehbarkeit von Verfahrensverstößen anderer Staaten zu begründen, hinausgeht ${ }^{183}$.

Dabei können sehr unterschiedliche Fragen auftreten, wie etwa die Relevanz von Entscheidungen in Gremien von Eurojust und Europol (oder im Rahmen von Gemeinsamen Ermittlungsgruppen) für die Bewertung der Rechtmäßigkeit von Maßnahmen, die sie ausgelöst haben. Wegen ihrer Einbettung in die RFSRZusammenarbeit müssten Verfahrensfehler im Ausland oder in supranationalen Agenturen für die innerstaatliche verfahrensrechtliche Bewertung fast schon wie eigene Verstöße zugerechnet und behandelt werden ${ }^{184}$. Bei koordinierten Ermittlungen zur Verfolgung von Verstößen gegen Unionsrecht stellt sich zudem die Frage, ob eine Berücksichtigung von Kumulierungseffekten ${ }^{185}$ erfolgen muss, die sich beispielsweise in einer Erweiterung etwaiger Verhältnismäßigkeitsabwägungen äußern muss. Die Komplexität der Zusammenarbeit auf überstaatlicher Ebene müsste auch in die Bewertung einfließen, ob ein Fall der notwendigen Verteidigung vorliegt.

183 Einzelne Rechte wie das Recht auf anwaltliche Vertretung wurden bereits mit der Abarbeitung der sog. roadmap sekundärrechtlich erweitert; im Überblick Frank Meyer, in: v. d. Groeben/ Schwarze/Hatje (Anm. 69), Art. 82 Rdn. 44ff.; Vogel/Eisele, in: Grabitz/Hilf/Nettesheim (Anm. 174), Art. 82 Rdn. 104 ff. Auch in der Rechtsprechung des EGMR finden sich erste Anklänge einer Berücksichtigung von Mängeln im Rechtshilfeverfahren, die auf die Verfahrensfairness im Verfolgerstaat ausstrahlen können; vgl. EGMR Urteil v. 27. 10. 2011 - 25303/08 (Stojkovic), NJW 2012, 3709, Rdn. 51f. Dessen Kerngedanke findet sich in Art. 14 Abs. 7 Satz 2 RL-EEA wieder; siehe unten Anm. Fn. 176.

184 Die Strukturen des Zusammenwirkens in einem gemeinsamen Strafverfolgungsraum legen eine einheitliche Bewertung der Verfahrensrechte und eine wechselseitige Zurechnung von Verstößen nahe; man kann nicht einerseits den Nutzen kumulieren und die Nachteile resp. Nebenwirkungen partikularisieren und isolieren. In dieser Hinsicht legt nunmehr auch Art. 14 Abs. 7 RL EEA fest, dass der Anordnungsstaat eine erfolgreiche Anfechtung der Anerkennung oder Vollstreckung einer EEA im Einklang mit seinem nationalen Recht berücksichtigt. Hierfür bietet die Vorschrift aber beträchtliche Flexibilität. Bei Feststellung von Verfahrensverstößen im Ausland sollte v.a. auf den Schutzzweck der dort verletzten Norm und deren Funktion für den inländischen Verfahrensgang abgestellt werden.

185 Darunter wird sowohl die Aggregierung der Wirkung einer Vielzahl von Eingriffen in dasselbe Rechtsgut in mehreren beteiligten Ländern als auch die gesamthafte Betrachtung multipler Eingriffe in unterschiedliche Grundrechte aufgrund unterschiedlicher Zwangsmaßnahmen verstanden. 


\section{e) Neutralisierung nationaler Sanktionsvorschriften durch Sekundärrecht oder Grundfreiheiten}

Bei der Neutralisierung nationaler Sanktionsvorschriften durch Sekundärrecht oder Grundfreiheiten stellt sich die Rechtslage auf den ersten Blick anders dar. Hier findet ein nationales Verfahren nicht zur Durchführung von Unionsrecht statt, sondern läuft der unionsrechtlichen Verpflichtung zum indirekten Vollzug von Sekundärrecht und Grundfreiheiten zuwider. Es geht aber auch hier um die zulässige Ausübung von Beschränkungsmöglichkeiten, die in Unionsrecht eingebettet ist und daher funktional gegenüber dem Bürger wiederum als Ausübung supranationaler Herrschaftsgewalt erscheint. Nicht geklärt ist damit, ob die Verfahrensrechte deshalb auch hier vollumfänglich gelten. Da die Ziehung der Strafbarkeitsgrenzen in diesen Fällen in den Anwendungsbereich des Unionsrecht fällt, ist die unionsrechtliche Fragestellung indessen nicht nur ein punktuell zu beachtender Rechtsaspekt; sie betrifft vielmehr den Kern des strafrechtlichen Vorwurfs, dessentwegen die Strafverfolgung überhaupt ins Laufen kam, konkret: das Vorliegen einer unionsrechtlich nicht gestatteten und damit grundsätzlich sanktionsfähigen Verhaltensnorm. Stützt der Beschuldigte sein Verteidigungsvorbringen auf die unionsrechtliche Zulässigkeit seines Verhaltens, dann müssen in diesem Zusammenhang auch die Justizgrundrechte der GRC gelten ${ }^{186}$. Die Anwendung und grundrechtsdogmatische Funktion materieller Grundrechte hängt dagegen, wie zuvor umrissen, maßgeblich von der jeweiligen Grundfreiheit und der fallspezifischen Rechtfertigung ihrer Beeinträchtigung $\mathrm{ab}^{187}$.

\section{f) Verfahrensbeendende Entscheidungen und Strafzumessung}

Bei verfahrensbeendenden Entscheidungen und bei der Strafzumessung kommen weitere Erwägungen ins Spiel. Führen die Mitgliedstaaten Unionsrecht durch, ist eine Ausstrahlung auf Entscheidungen über Einstellung, Anklage oder Verständigungen vorstellbar. Die wirksame Durchsetzung des Unionsrechts kann eine effektive Strafverfolgung und ggf. Anklageerhebung gebieten und deshalb die üblichen nationalrechtlichen Entscheidungsparameter überformen $^{188}$. Der Wirksamkeitsgrundsatz kann das staatsanwaltliche oder gerichtliche Ermessen gerade in Bezug auf die Anwendung der Opportunitätsvorschriften in gewisse Richtungen lenken oder gar auf Null reduzieren, wenn es notwendig

186 ... und ggf. auch materielle Grundrechte einfließen. Dies kann aber je nach Sachlage zur Stärkung der Grundfreiheit oder zur Rechtfertigung des Eingriffs geschehen.

187 Siehe oben S. $1091 \mathrm{ff}$.

188 Vgl. Frank Meyer, in: v. d. Groeben/Schwarze/Hatje (Anm. 69), Art. 83 Rdn. 4, 60. 
erscheint, um die Wirksamkeit des Unionsrechts durch eine entschlossene Durchsetzung des unionsrechtlich durchwirkten Strafanspruchs zu verbürgen. Anders als im Verwaltungsrecht ist dieser Zusammenhang im Strafverfahrensrecht noch nicht angemessen rezipiert worden. Die unterschiedlichen Finalitäten der EU-induzierten Strafnormen und die damit verbundenen divergierenden Grade an Determiniertheit und Durchsetzungsorientiertheit machen eine differenzierende Betrachtung notwendig. $\mathrm{Zu}$ unterscheiden ist vor allem zwischen Straftatbeständen, die der Verbesserung der strafrechtlichen Zusammenarbeit bei der transnationalen Kriminalität dienen, und solchen, die einen durchsetzungsorientierten, akzessorischen Schutz von Unionsinteressen, -politiken und -prinzipien bezwecken ${ }^{189}$. Bei letzteren werden regelmäßig engere fachrechtliche Vorgaben bestehen. Zudem setzt die Kompetenzausübung Unerlässlichkeit des Strafrechtsschutzes voraus, was sich auf Implementierungsebene auswirken muss.

Das Effektivitätsprinzip kann dabei nicht nur in den Bahnen des geltenden nationalen Rechts wirken. Es kann ggf. sogar zu dessen Unanwendbarkeit führen. So beschied der EuGH jüngst der italienischen Justiz, dass man nationales Verjährungsrecht unangewendet zu lassen habe, wenn dieses die wirksame Durchsetzung von Unionsrecht verhindert. Der EuGH vermerkt aber zutreffend, dass dabei die Grenzen der GRC einzuhalten wären. Allgemein gilt, dass die sachlich berührten Unionsgrundrechte in diesen Situationen als (das Wirksamkeitsgebot) verstärkende Rechte oder als begrenzende Rechte auftreten können. Im Fall „Taricco“ übersieht der EuGH insofern, dass der Fairnessgrundsatz nach der vermittels Art. 52 Abs. 3 GRC bindenden Rechtsprechung des EGMR nach einer rechtlichen Fixierung der Verjährungsfristen verlangt. Über den Wirksamkeitsgrundsatz ist keine hinreichend verlässliche Bestimmung der zeitlichen Grenzen der Verfolgung möglich; seine Anwendung führt gerade zu deren Pulverisierung. Die Kernaussagen des Urteils scheinen sich daher nur schwer mit Art. 47 GRC vereinbaren zu lassen ${ }^{190}$.

Der Wirksamkeitsgrundsatz lässt auch Sanktionsentscheidungen nicht unberührt. Er kann die Rechtsanwendung der nationalen Stellen in gewisse Richtungen drängen, um spezifische unionale Sanktionsbedürfnisse zu befriedigen. Diese können rein funktionalistisch auf die wirksame Durchsetzung von Unionsrecht, aber auch expressiv auf die Untermauerung der Schwere der Rechtsgutsverlet-

189 Dazu Frank Meyer (Anm. 108), S. $455 \mathrm{ff}$. Zu unterscheiden ist vor allem zwischen Straftatbeständen, die der Verbesserung der strafrechtlichen Zusammenarbeit bei der transnationalen Kriminalität dienen, und solchen, die einen durchsetzungsorientierten akzessorischen Schutz von Unionsinteressen, -politiken, -prinzipien bezwecken.

190 Siehe Anm. 182. 
zung gerichtet $\operatorname{sein}^{191}$. Sachlich einschlägige GRC-Rechte kommen dann erneut verstärkend oder begrenzend zum Zug. Insb. wäre Art. 49 Abs. 3 GRC im Rahmen gerichtlicher Strafzumessungsentscheidungen heranzuziehen ${ }^{192}$. Dies hätte aber relativ zu dem durchzuführenden Unionsrecht zu geschehen, denn die Bemessung von objektivem Unwertgehalt, Strafzweck und Sanktionsbedürfnis orientiert sich wiederum an Unionsrecht! Welches Rechtsgut zu schützen ist, welche Wertigkeit diesem zuzuschreiben ist und welche allgemeine sanktionsrechtliche Zielsetzung mit der Bestrafung verfolgt wird, bemisst sich primär nach dem durchzuführenden Fachrecht der $\mathrm{EU}^{193}$. Hierdurch kann es durchaus auch zur Transformierung nationaler kriminalpolitischer Ansätze und Sanktionsverständnisse kommen, soweit das Unionsrecht eine anders ausgerichtete Implementierung verlangt ${ }^{194}$. $\mathrm{Zu}$ klären wäre dann, ob nicht materielle Rechte der GRC eine Abweichung rechtfertigen.

\section{Verhältnis zum nationalen Verfassungsrecht}

Zur Anwendbarkeit der nationalen Grundrechte bleibt zu vermerken, dass ein Rückgriff auf nationales Verfassungsrecht nur dort und in dem Umfang versperrt ist, wo im konkreten Fall eine Kollisionslage mit Unionsgrundrechten besteht oder Vorrang, Einheitlichkeit und Wirksamkeit des Unionsrechts hierdurch beeinträchtigt würden. Die maßgeblichen Grenzen müssten freilich wiederum in jedem Einzelfall ausgelotet werden. Vielfach dürfte es zu einer parallelen Geltung der korrespondierenden nationalen Grundrechte kommen. Wie der kürzlich vom Bundesverfassungsgericht entschiedene Fall einer Auslieferung zur Strafvollstreckung eines Abwesenheitsurteils illustriert, kann diese Fortgeltung für den Betroffenen ein Segen sein, wenn der Schutz der zuständigen nationalen Instanzen ausfällt und ein Verfassungsgericht bei bestehendem Anwendungsvorrang (und mangels direkter Zuständigkeit für die Durchsetzung der GRC) gar nicht zulässig mit solchen Fällen hätte befasst werden können ${ }^{195}$. Eine prioritäre Geltung, die aus Sicht des Bundesverfassungsgerichts auch nicht auf Vorrang und Wirksamkeit von Sekundärrecht Rücksicht zu nehmen braucht, ist dagegen den identitäts-

191 Dazu auch Frank Meyer, in: v. d. Groeben/Schwarze/Hatje (Anm. 69), Art. 83 Rdn. 58f.; explizit zum expressiven Strafverständnis der EU auch Turner, The Expressive Dimension of EU Criminal Law, American Journal of Comparative Law, Vol. 60 (2012), S. 555, 572f., 582f.

192 Eser, in: Jürgen Meyer (Anm. 6), Art. 49 Rdn. 38; Jarass (Anm. 12), Art. 49 Rdn. 4.

193 Telos und gesetzgeberische Intention sind durch das Gericht zu ermitteln.

194 In diese Richtung schon Dannecker, ZStW 117 (2005), S. 697, 747.

195 Zum Potenzial dieser Linie Frank Meyer, NJECL 7 (2016), S. 277, $292 \mathrm{ff}$. 
stiftenden Verbürgungen des Grundgesetzes vorbehalten. Es kann derzeit jedoch nur spekuliert werden, welche Fälle künftig vom Menschenwürdevorbehalt erfasst werden könnten. Durch Verknüpfung mit dem Schuldprinzip kommt diesem die (potenzielle) Wirkung eines Turboladers zu, der auch zahlreiche Konstellationen in den Anwendungsbereich des Identitätsvorbehalts spült, die für gewöhnlich mit anderen Grundrechten verbunden werden ${ }^{196}$. Im Auslieferungsverfahren können beispielsweise defizitäre Nachprüfungsmöglichkeiten bei Abwesenheitsentscheidungen, menschenunwürdige Haftbedingungen, mit massiven Verfahrensfehlern behaftete Urteile (flagrant denial of justice) schon jetzt als Vollstreckungshindernisse in Betracht kommen. Wollte das Bundesverfassungsgericht darüber hinaus sein Verständnis von materieller Wahrheit und schuldgetragenen Ermittlungspflichten vollumfänglich zum Maßstab machen, drohten erhebliche Verwerfungen, weil damit die Kooperationsfähigkeit in Frage gestellt wäre, wenn im ausländischen Verfahren Abspracheverfahren oder Zurechnungsfiguren zur Anwendung kamen oder kommen könnten, die mit dem deutschem Verständnis von materieller Wahrheit bzw. Schuld unvereinbar sind.

In der Sache schwächt dieser prononcierte Exklusivitätsanspruch den gemeinsamen europäischen Grundrechtsschutz. Anstatt sich in ein Verbundsystem gemeinsamen europäischen Grundrechtsschutzes einzufügen und anschlussfähige, konstruktive Beiträge zu dessen Ausbau zu leisten, wird die Relevanz der GRC marginalisiert und es wird auf einseitige nationale Lösungen gesetzt ${ }^{197}$.

\section{Schlussbetrachtungen}

Die Analyse hat aufgezeigt, dass im nationalen Straf- und Strafverfahrensrecht sehr weitreichende und komplexe Bindungen an die GRC bestehen. Um die möglichen Konsequenzen einer GRC-Bindung in ihrer ganzen Breite und Tiefe zu erkennen und auf sie adäquat zu reagieren, bedarf es jedoch eines Perspektivwechsels bei den staatlichen Strafjustizakteuren ${ }^{198}$. Diese scheinen die GRC gegenwärtig noch nicht vollständig in ihr strafprozessuales Denken integriert zu haben. Es herrscht eine Wahrnehmungsverzögerung vor, die einen Entwicklungsstau zur Folge hat. Die Mitgliedstaaten wähnen sich offenbar noch in der dritten Säule und nehmen ihr Handeln vielfach noch nicht als Ausübung supranationaler Hoheitsgewalt wahr. Es besteht daher aktuell die Gefahr, dass die supranationale

196 Zur potenziellen Reichweite Frank Meyer, HRRS 2016, 332, 337; ausf. Kritik an der Überhöhung nationaler Konzepte bei Brodowski, JR 2016, 415, 427 ff.

197 Kritik bei Frank Meyer HRRS 2016, 332, 339.

198 Vgl. auch Gaede (Anm. 54), Bd. 9, § 3 Rdn. 53. 
Grundrechtsdimension des eigenen Handelns weiterhin ausgeblendet wird. Der Konzeption des Grundrechtsschutzes in der Union entspricht das nicht: Der EuGH hält in „Åkerberg Fransson“ zutreffend fest, „,dass das Unionsrecht einer Gerichtspraxis entgegensteht, die die Verpflichtung des nationalen Gerichts, Vorschriften, die gegen ein durch die Charta garantiertes Grundrecht verstoßen, unangewendet zu lassen, davon abhängig macht, dass sich dieser Verstoß klar aus den Bestimmungen der Charta oder aus der entsprechenden Rechtsprechung ergibt, da sie dem nationalen Gericht die Befugnis abspricht - gegebenenfalls in Zusammenarbeit mit dem Gerichtshof - die Vereinbarkeit dieser Bestimmung mit der Charta umfassend $\mathrm{zu}$ beurteilen“199. Es besteht also nicht nur eine Prüfungsbefugnis, sondern eine Prüfungspflicht nationaler Gerichte. Gleichwohl trägt auch die Rechtsschutzarchitektur der EU zum Problem bei. Sie führt (beim indirekten Vollzug) zu einer Spaltung von Abwehr- und Leistungsfunktion der Grundrechte. Nationalstaaten sorgen sich im herrschenden Modell allenfalls um etablierte Abwehrfunktionen, während der eigentlich für die Leistungsdimension zuständige EuGH keine Fälle erhält, wenn nationale Gerichte die Vorlagerelevanz nicht erkennen. Gerade für Organisations- und Verfahrensfragen ist die die Schutzfunktion indessen sehr wichtig ${ }^{200}$; häufig offenbaren sich erst in der Vollzugsphase Mängel der Verfahrensinfrastruktur oder sonstige Defizite bzgl. der Möglichkeiten, bestimmte materielle Rechte zu realisieren. Eine Mobilisierung der Bürger für die Durchsetzung ihrer eigenen Rechte ${ }^{201}$ scheidet als Alternative in dieser Situation ebenfalls weitgehend aus, weil kaum effektive Einflusskanäle existieren.

Doch selbst wenn eine Erweiterung des Blickwinkels einträte, stellten sich einige konstruktive Probleme: Wie lassen sich neue Gefährdungslagen grundrechtsdogmatisch verarbeiten? Kann Grundrechtsdogmatik überhaupt Lückenfüllung und Ausgleich leisten? Welche Spielräume genießen Nationalstaaten bei der Realisierung ${ }^{202}$ ? Diese Aufgabe könnte die Kapazitäten und Kompetenzen nationaler Gerichte überstrapazieren. In nicht wenigen Bereichen müsste Neuland betreten werden, z. B. beim Eingriffsbegriff. In den meisten Fällen wird daher eine Vorlage an den EuGH indiziert sein. Gefordert ist in diesem Zusammenhang aber vor allem auch die EU-Gesetzgebung. Sie müsste sich ernsthafter mit der Rechtsstellung Betroffener in der spezifischen Situation EU-induzierter und insb. grenz-

199 EuGH, Rs. C-617/10 (Åkerberg Fransson), Rdn. 48.

200 Kingreen, in: Calliess/Ruffert (Anm. 9), Art. 51 Rdn. 24.

201 Masing, Die Mobilisierung des Bürgers für die Durchsetzung des Rechts: Europäische Impulse für eine Revision der Lehre vom subjektiv-öffentlichen Recht, Freiburg 1997.

202 Zum margin of appreciation siehe oben Anm. 69; die Kontrolldichte muss mit Wollenschläger zutreffend höher ausfallen als vor dem EGMR, weil im untersuchten Zusammenhang die „,systeminterne Kontrolle im Vordergrund“ stünde (Anm. 18), Bd. 1, § 8 Rdn. 77. 
überschreitender Strafverfahren befassen ${ }^{203}$ und der Gestaltungsverantwortung nachkommen, die ihren positiven grundrechtlichen Schutzpflichten entspringt. Bislang nimmt der EuGH eine Ableitung von derartigen Schutzpflichten nur aus Grundfreiheiten vor; für Grundrechte wurde diese Funktion noch nicht entfaltet ${ }^{204}$. Ein Vorbild dafür bildet der EGMR, der wiederholt die zuständigen Organe unter Druck gesetzt hat, längst überfällige positivrechtliche Änderungen vorzunehmen.

203 Frank Meyer, in: v. d. Groeben/Schwarze/Hatje (Anm. 69), Vor Art. 82ff. Rdn. 35: „Der Grundrechtsschutz ist bei der Nutzung und Umsetzung supranationaler Instrumente und Kooperationsformen in Art. $67 \mathrm{ff}$. AEUV effektiv auf die Grundrechte und Grundfreiheiten der Unionsbürger auszurichten. Gem. Abs. 2 Präambel GRC stellt die Union ausdrücklich den Menschen in den Mittelpunkt ihres Handelns und ihrer Normordnung, was sich auch bei der polizeilichen und justiziellen Zusammenarbeit realisieren muss. Der Mehrwert einer so erreichten Grundrechtsbindung läge in der Gewährleistung eines gefährdungsadäquaten und raumweit einheitlichen Schutzes von Grundrechten und Grundfreiheiten, wie ihn nationale Grundrechte und EMRK kaum bieten, sowie der Eröffnung der entsprechenden Rechtsschutzkanäle des Unionsrechts zur Sicherung der Freiheit der Unionsbürger.“; siehe auch Zeder, EuR 2012, 34, 59.

204 Kingreen, in: Calliess/Ruffert (Anm. 9), Art. 51 Rdn. 25 f. 